\title{
Motion detection using near-simultaneous satellite acquisitions
}

\author{
Andreas Kääb ${ }^{\mathrm{a}^{*}}$ and Sébastien Leprince ${ }^{\mathrm{b}}$
}

a Department of Geosciences, University of Oslo, P.O.Box 1047, Oslo, Norway;

kaeaeb@geo.uio.no; phone: +47 22855812

*(corresponding author)

b Division of Geological and Planetary Sciences, California Institute of Technology, MC 100-23, 1200 E. California Blvd., Pasadena, CA 91125, USA;

leprincs@caltech.edu

\begin{abstract}
A number of acquisition constellations for airborne or spaceborne optical images involve small time-lags and produce near-simultaneous images, a type of data which has thus far been little exploited to detect or quantify target motion at the Earth's surface. These time-lag constellations were for the most part not even meant to exhibit motion tracking capabilities, or these capabilities were considered a drawback. In this contribution, we give the first systematic overview of the methods and issues involved in exploiting near-simultaneous airborne and satellite acquisitions. We first cover the category of the near-simultaneous acquisitions produced by individual stereo sensors, typically designed for topographic mapping, with a time-lag on the order of a minute. Over this time period, we demonstrate that the movement of river ice debris, sea ice floes or suspended sediments can be tracked, and we estimate the corresponding water surface velocity fields. Similarly, we assess cloud motion vector fields and vehicle trajectories. A second category of near-simultaneous acquisitions, with much smaller time-lags of at most a few seconds, is associated with along-track offsets of detector lines in the focal plane of pushbroom systems. These constellations are demonstrated here to be suitable to detect motion of fast vehicles, such as cars and airplanes, or, for instance, ocean waves. Acquisition delays are, third, also produced by other constellations such as 'trains' of satellites following each other and leading to time-lags of minutes to tens of minutes, which are in this contribution used to track icebergs and features of floating ice crystals on the sea, and an algae bloom. For all acquisition categories, the higher the spatial resolution of the data and the longer the time-lag, the smaller the minimum speed that can be detected.
\end{abstract}

Keywords: stereo, focal plane, time-lag, water velocity, river ice, suspended sediments, algae bloom, cloud motion, vehicle motion

Figures and animations for all sets of near-simultaneous images used can be found under http://folk.uio.no/kaeaeb/publications 
Kääb A. and Leprince S. (2014): Motion detection using near-simultaneous satellite acquisitions.

Remote Sensing of Environment, 154, 164-179. DOI: 10.1016/j.rse.2014.08.015 (Initial manuscript version).

\section{Introduction}

Lateral motions on the Earth's surface happen at a large range of magnitudes and rates. The ability to quantify them from ground, air or space using repeat imagery depends, in principle, on the precision of the method used, the total displacement between two data acquisitions, the rate of displacement, and the existence of corresponding features in phase data (for radar) or amplitude data (for radar and optical sensors) that can be tracked over time. For instance, tectonic displacements, glacier flow, rockglacier creep, slow landslides or soil motion are typically measured using radar interferometry (e.g., Rott 2009), or optical or radar offset tracking methods (e.g., Kääb 2002; Kääb et al. 2014; Leprince et al. 2007b; Strozzi et al. 2002). Depending on the displacement rates and the visual or phase coherence over time, the temporal baselines applied may vary significantly, typically from days to years. In the following, we refer to temporal baselines as time-lags.

Much research and applications are available for timelags of weeks to years and decades from air and space, or for ground or laboratory applications with a range of typically shorter time-lags (e.g., particle image velocimetry, PIV). Short airborne or spaceborne timelags on the order of milliseconds to minutes, up to a few hours, and their application to Earth surface processes are, however, very little and not systematically exploited. Such near-simultaneous data have, however, the potential to depict motion and processes that could so far hardly be quantified over larger areas. Along-track radar interferometry has, for instance, been demonstrated for ocean currents, river flow and vehicle movement (Baumgartner and Krieger 2011; Goldstein and Zebker 1987; Romeiser et al. 2007; Romeiser et al. 2010; Siegmund et al. 2004). Also, synthetic aperture radar (SAR) processing, which is based on the Doppler effect, displaces moving objects depending on the additional Doppler effect they introduce in the processing.

The present overview focuses on optical data with airborne and spaceborne time-lags on the order of milliseconds to minutes. A few related studies are currently available with specific applications to river ice debris (Beltaos and Kääb 2014; Kääb et al. 2013; Kääb and Prowse 2011), ships (Takasaki et al. 1993), cars (Reinartz et al. 2006), sun glitter (Matthews and
Awaji 2010), and waves (De Michele et al. 2012). These studies are referred to in more detail later in this contribution. This article gives the first systematic overview on short acquisition time-lags in Earth observation datasets, and demonstrates a number of novel applications. Typically, these time-lags stem from constellations that are for the most part not meant for motion tracking or where time-lags are even considered a drawback. First, we will elaborate on the acquisition constellations that cause time-lags. After describing methods that can be used to explore and quantify motion in near-simultaneous data, we demonstrate and discuss a selection of applications using case studies.

\section{Near-simultaneous acquisition constellations}

Short optical time-lags arise from two acquisition principles:

A first principle of time-lags, which is however not the main focus of this contribution, stems from repeat acquisitions from, at least approximately, stationary sensors (with respect to the Earth surface), such as on balloons, zeppelins, helicopters, satellites with video devices, or satellites in geostationary orbits. Exploitation of time-lag data from geostationary platforms is well established from weather satellites to monitor cloud motion, but also instruments for higher resolution and thus with smaller movements becoming detectable are under consideration (Michel et al. 2013). Time-lag data can also be achieved through revisit of an acquisition position by the same or another platform within short time (e.g., different satellites following each other on similar orbit, 'trains'; repeat airphoto flight lines).

A second principle, and the main focus of this contribution, consists in along-track angular differences between the acquisition directions of two or more images (Fig. 1). The effective time-lag is then primarily a function of the difference in looking angles to the target, the average speed of the sensor between acquisitions and its height above target. Further influences on the time-lag stem from the deviation of the sensor flight path from a straight line or arc, and from the geometry of the angular constellation (Fig. 2). 


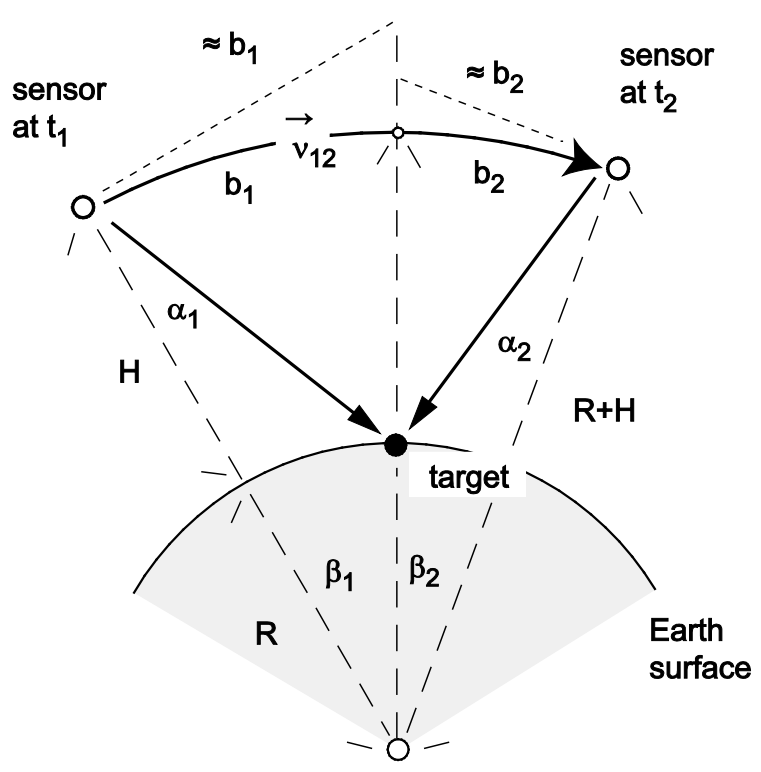

Earth center

Fig. 1 Scheme of a single-pass near-simultaneous acquisition causing a time-lag $t_{2}-t_{1}$. Earth radius $R$, flying height above Earth surface $H$, angles $\alpha$ and $\beta$, and arc $b$.

The time-lag can be estimated from the looking angles as follows. For a geocentric circular orbit around Earth (Fig. 1)

$b=b_{1}+b_{2}=\left(\beta_{1}+\beta_{2}\right)(R+H)$

where $b$ is the length of an arc between two oblique acquisition looks, $\beta_{1}$ and $\beta_{2}$ the corresponding angles (in radians) at Earth centre against nadir, $R$ the Earth radius and $H$ the sensor height above Earth surface.

The time difference between the views is for an average sensor speed $|\vec{v}|$

$\Delta t=t_{2}-t_{1}=\frac{b}{|\vec{v}|}$

For $H \ll R$ the $\operatorname{arcs} b_{1}$ and $b_{2}$ (Eq. 1) can be approximated as $b_{1} \approx \sin \beta_{1}(R+H)$ and $b_{2} \approx \sin \beta_{2}(R+H)$, respectively, and thus

$b \approx H\left(1+\frac{H}{R}\right)\left(\tan \alpha_{1}+\tan \alpha_{2}\right)$.

The average speed $|\vec{v}|$ of a sensor orbiting around Earth can be approximated using Kepler's third law

$$
\frac{T^{2}}{(R+H)^{3}}=\frac{4 \pi^{2}}{G M}
$$

(with $T$ being the time for one orbit around Earth, $G$ the gravitational constant and $M$ the Earth mass) by dividing the full circumference of one orbit by $T$ to be

$|\vec{v}|=\sqrt{\frac{G M}{(R+H)}}$

Inserting Eqs. (3) and (5) into (2) finally gives

$\Delta t \approx\left(\tan \alpha_{1}+\tan \alpha_{2}\right) \frac{H}{R} \sqrt{\frac{(R+H)^{3}}{G M}}$

which can be used to estimate the acquisition time-lag between two oblique views (with $G M=3.98$. $\left.10^{14} \mathrm{~m}^{3} \mathrm{~s}^{-2}, R=6371 \cdot 10^{3} \mathrm{~m}\right)$. For constellations with an oblique and a nadir view, one of the two sets of $b, \alpha$ and $\beta$ become zero, depending on whether the system is forward or backward looking.

Angular near-simultaneous acquisition constellations serve very different purposes such as stereo acquisitions for topographic mapping (Fig. 2 a-c,e-f), investigations of bi-directional reflection distribution, or measurement of atmospheric effects (Fig. 2 d). Several constellations (e.g., Fig. 2 a-d, f, g, k) are able to acquire long swaths of near-simultaneous data, hundreds of kilometres for instance (Kääb et al. 2013), depending on the acquisition capacities of the system. Some angular constellations with particularly small angles are due to necessity without further purpose other than solving constraints in sensor construction, for instance small along-track offsets of the detector lines of different bands in the focal plane of multispectral pushbroom sensors without beam splitter (Fig. 2 k).

\section{Methods}

\subsection{Geometric distortions}

The displacements of targets between repeat imagery can be directly exploited if the data are taken from the same sensor position. Acquisitions from different positions involve perspective and altitudinal image distortions. Perspective distortions can be removed in case of known or re-constructed sensor and acquisition geometry. Altitudinal distortions require knowledge of target elevations and removal of the altitudinal 
Kääb A. and Leprince S. (2014): Motion detection using near-simultaneous satellite acquisitions.

Remote Sensing of Environment, 154, 164-179. DOI: 10.1016/j.rse.2014.08.015 (Initial manuscript version).

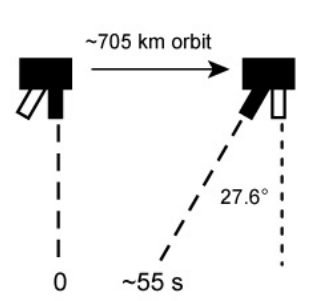

(a)

fixed along-track stereo:

ASTER

\section{(C)}

fixed along-track stereo:

ALOS PRISM

$0 \sim 45 \sim 90 \mathrm{~s}$

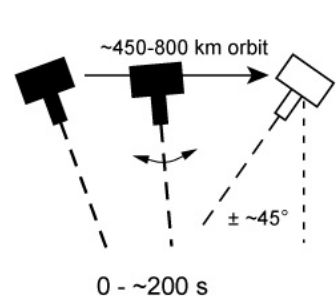

(e)

\section{steerable} along-track stereo: e.g., Ikonos, WorldView, Pleiades, handheld air or spacecameras
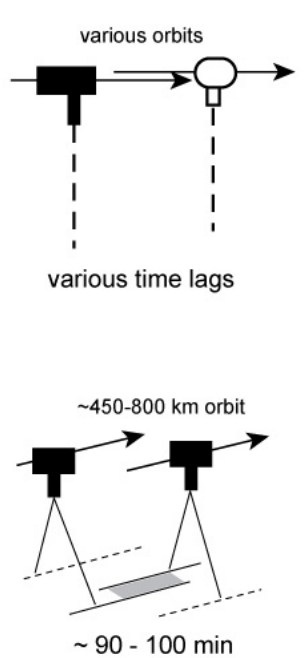

\section{(g)}

tandem constellations: e.g., ASTERLandsat7 15-30 min

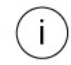

airborne or satellite cross-track stereo, e.g., neighbour orbits or flight lines

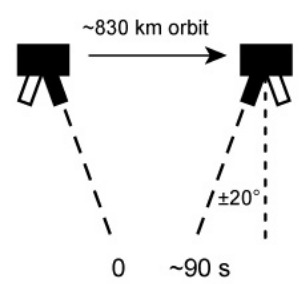

(b)

fixed along-track stereo:

SPOT5 HRS

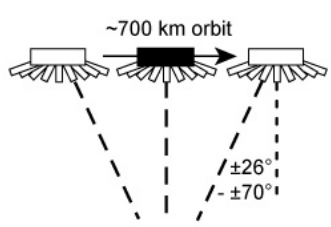

(d)

fixed along-track stereo: MISR

$$
0-\sim 570 \mathrm{~s}
$$
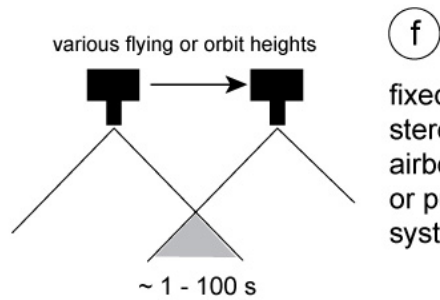

fixed along-track stereo of airborne frame or pushbroom systems

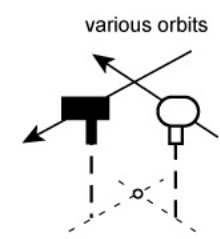

(h) airborne or satellite cross-overs, e.g., ascending and descending orbits

various time lags

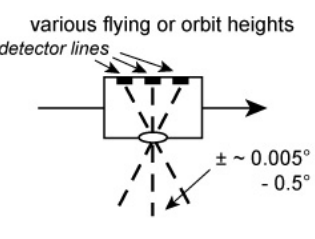

(k)

along-track offsets of detectors in focal plain: e.g., WorldView, Rapideye, $\sim 0.01-2 \mathrm{~s}$

Sentinel-2

Fig. 2 Overview of acquisition constellations that cause time-lags of minutes and smaller, here referred to as nearsimultaneous acquisitions. See text for sensor abbreviations.

component (height parallax) in the raw displacement field, typically through orthorectification, unless the investigated site can be assumed to be a plane. Under the latter assumption, the two or more repeat images can be directly co-registered using stable tie-points and a first-order polynomial transformation. Such transformation describes the projection of two, not necessarily horizontal, planes onto each other. As a whole or piecewise, the assumption of a planar study site will for instance typically hold for water surfaces. 


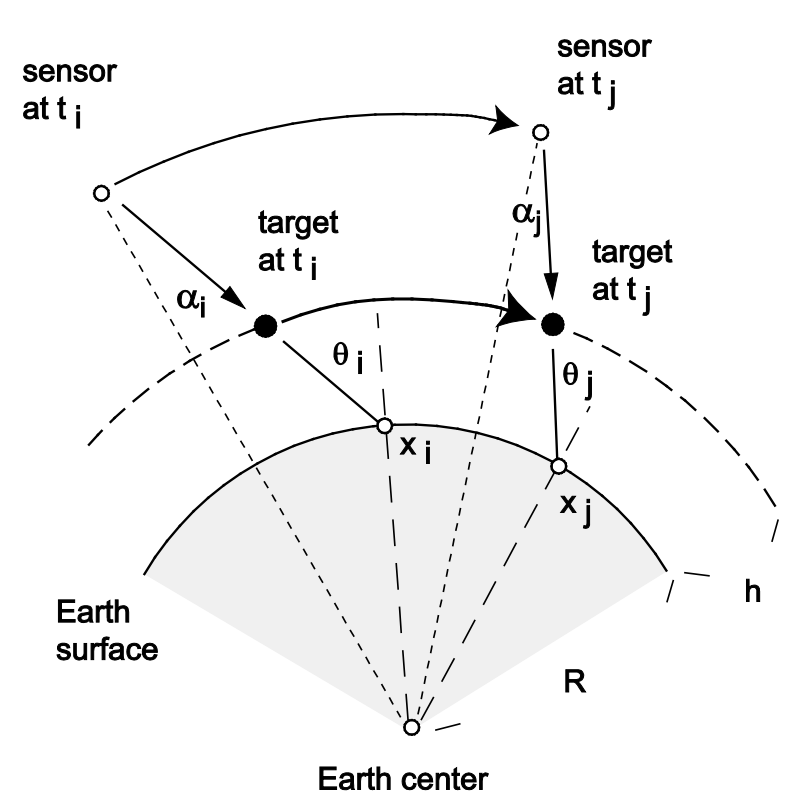

Fig. 3 Two views on a target moving at height $h$. Target height and motion can be estimated simultaneously if three or more views from different directions are available. After Horvath and Davies (2001).

Only in few cases of large scenes, high spatial image resolution and high tracking precision needed, it might be necessary to consider Earth curvature, e.g., by using a second-order polynomial co-registration. The effects from unknown or inaccurate target elevation on the motion measurement are discussed below under error influences (section 3.4).

In most near-simultaneous constellations, target elevation will have to be known, estimated, or its influence eliminated or at least reduced by coregistration of the images. Under certain geometric conditions, though, it is possible to estimate target motion and elevation simultaneously. This approach is a standard procedure for the Level 2 products of simultaneous cloud winds and heights from the Multiangle Imaging SpectroRadiometer (MISR) data (Diner et al. 1999; Horvath and Davies 2001).

For the two-dimensional case, and under the conditions that target height $h$ remains constant over the time lag, that $h \ll R$, and that the target speed is constant, Horvath and Davies (2001) showed that

$d_{j i}=d\left(t_{j}-t_{i}\right)=\left(x_{j}-x_{i}\right)+h\left(\tan \theta_{i}-\tan \theta_{j}\right)$

where $d\left(t_{j}-t_{i}\right)$ is the along-track motion (i.e. motion in epipolar direction) of the target at height $h, \theta$ the angle between nadir and the ray from ellipsoid through the target to the sensor at times $i$ and $j$, respectively (incidence angle), and $x$ the projection of the target onto the ellipsoid at times $i$ and $j$, respectively (Fig. 3). The disparity $\left(x_{j}-x_{i}\right)$ can be measured and $\theta$ is known from the constellation, attitude and pointing angle measurements, or from image orientation, so that the two unknowns $d_{j i}$ and $h$ can be computed if three or more views on the target are available. The linear equation system Eq. (7) becomes, however, singular, i.e. the equations dependent on each other, if the viewing constellation is symmetric to nadir and the sensor flight line a straight line. The latter condition limits the applicability of the approach in general to orbital sensors. Horvath and Davis (2001) also generalize the above two-dimensional along-track case to the full three-dimensional one that includes also cross-track components of target motion.

\subsection{Visualization of motion}

If geometric distortions between the repeat data are removed, displacements in time-lag images can be qualitatively explored using visualisation or change detection methods:

- image flickering, or animations (Beltaos and Kääb 2014; Kääb et al. 2013);

- multi-temporal colour composites (Fig. 17 and Fig. 19) (Matthews and Awaji 2010). This technique leads to coloured duplicates of the targets in the composite or colour frames, also sometimes called halos, around the targets;

- multi-temporal anaglyph images. Using red-cyan glasses, the displacement component in the epipolar plane of the human eyes appears then as elevated, proportional to the magnitude of the displacement component (Fig. 6);

- standard change detection techniques such as band ratios or (normalized) difference indexes.

\subsection{Image matching}

Displacements in near-simultaneous images can be quantified using image matching techniques. These techniques are usually separated into area- (or block-) based and feature-based techniques (Brown 1992; Heid and Kääb 2012; Zitova and Flusser 2003). Both techniques can be suitable for displacements from short time-lags. One type of displacements stems from motion of continuous or large-scale objects such as clouds, waves etc., where traditional area-based 
Kääb A. and Leprince S. (2014): Motion detection using near-simultaneous satellite acquisitions.

Remote Sensing of Environment, 154, 164-179. DOI: 10.1016/j.rse.2014.08.015 (Initial manuscript version).

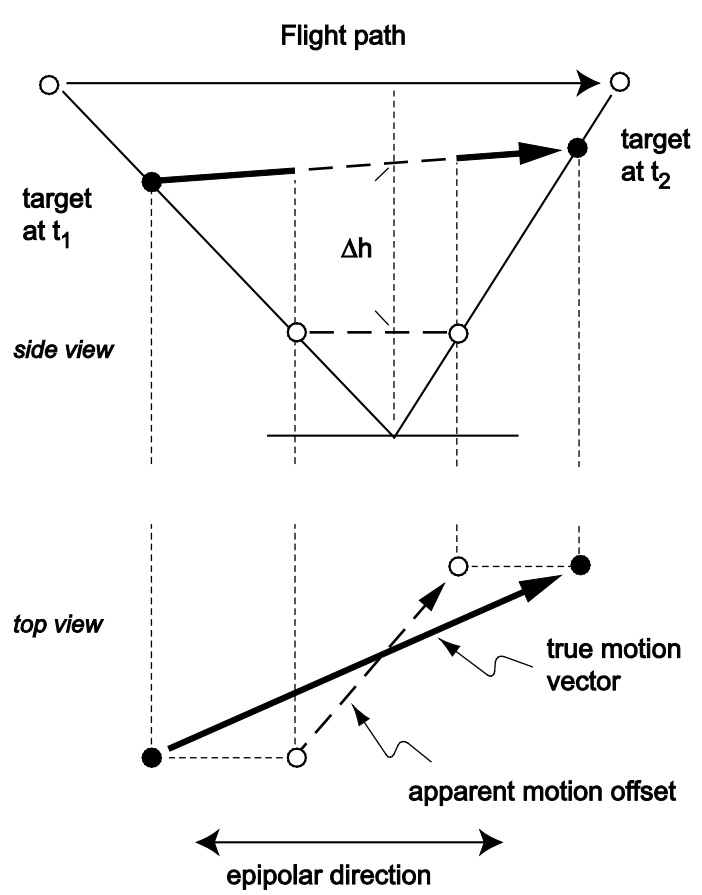

Fig. 4 Influence of target elevation on displacements estimated from angular time-lags. Upper part side view, lower part top view.

matching techniques seem suitable to provide displacements at sub-pixel accuracy (cf. Diner et al. 1999). Feature-based matching techniques may in parts be preferable for a second target type of small discrete objects such as vehicles, often covering only a few pixels.

The displacement examples in this contribution are obtained using Normalized Cross-Correlation (NCC) and Orientation Correlation (CCO). NCC is a standard technique and we use the implementation by Kääb and Vollmer (2000) and Debella-Gilo and Kääb (2011). CCO does not applies cross-correlation to the raw imagery but rather to orientation images, which are complex images of the signs $[-1,0,+1]$ of $x-$ and $y-$ gradients (Fitch et al. 2002; Heid and Kääb 2012). CCO turned out to be preferable for images with weak visual contrast, e.g., clouds (Fig. 14).

\section{$3.4 \quad$ Error budget}

\subsubsection{Target elevation}

For angular time-lags, target offsets between the repeat imagery can, strictly, only be converted to ground velocities if the target elevation is known at each time of imagery, or can be determined simultaneously with the target motion. Target elevation errors translate to positional, and thus to velocity errors, according to the base-to-height ratio of the angular constellation (Fig. 4). For ellipsoidprojected images from the Advanced Spaceborne Thermal Emission and Reflection radiometer (ASTER; Level 1B), for instance, with a base-toheight ratio of $\sim 0.6$, an error of $100 \mathrm{~m}$ in mean target elevation (here termed absolute elevation error) causes an error vector of $60 \mathrm{~m}$ in along-track direction. The influence of this error vector on target displacement magnitude, and thus speed, therefore depends on the direction of the target motion with respect to the epipolar direction of the angular constellation, with smallest influences for motions in cross-track directions. Errors in mean target elevation can therefore have substantial impact for large base-toheight ratios and have to be corrected unless the images used are sufficiently orthorectified.

Relative, i.e. local elevation errors, for instance due to (i) local DEM errors or vertical residuals of the observed topography from an assumed planar surface, due to (ii) temporal elevation variations of the target during the observation time-lag, or (iii) if the DEM used for orthorectification is outdated with respect to the acquisition time, analogously translate to displacement and velocity errors depending on the base-to-height ratio of the constellation. Stereo constellations with a typical base-to-height ratio on the order of $\sim 0.5-1$ are therefore very sensitive to relative errors in target elevation, but constellations with detector offsets in the focal plane with base-to-height ratios on the order of $\sim 10^{-2}$ or smaller are so only very little (De Michele et al. 2012; May and Latry 2009).

\subsubsection{Sensor errors}

A second category of errors comes from geometric sensor errors such as (i) scanner noise, (ii) sensor jitter, and (iii) band-to-band misregistration. (i) For scanning instruments such as Landsat Thematic Mapper (TM) and Enhanced Thematic Mapper (ETM), noise in ground projected pixel positions stems among others from noise induced by the scanning mechanics. The image-to-image coregistration accuracy for Landsat data, for instance, is given to be on the order of a third of a pixel (Lee et al. 2004). (ii) For pushbroom sensors, platform jitter can be a substantial source of noise in pointing accuracy, reaching for instance up to 1-2 pixels in horizontal displacement for ASTER (Kääb et al. 2013). 
Kääb A. and Leprince S. (2014): Motion detection using near-simultaneous satellite acquisitions.

Remote Sensing of Environment, 154, 164-179. DOI: 10.1016/j.rse.2014.08.015 (Initial manuscript version).

Depending on its frequency, jitter can, in principle, be determined statistically from disparity fields between the repeat images and be corrected (Kääb et al. 2013; Leprince et al. 2007a; Nuth and Kääb 2011). (iii) Where motion offsets are determined from band-toband offsets in the focal plane, errors in groundprojected positions may stem from insufficient registration models between the bands exploited. Again, such registration errors can, in principle, be estimated from the disparity field over stable ground.

\subsubsection{Target matching}

A third error category in the determination of motion is the precision with which the offsets between corresponding targets can be measured. In case of image matching techniques, this precision can be as low as on the order of $\sim 0.1$ pixel or better, and are thus a minor effect in the total error budget of motion determination (Kääb et al. 2013). The matching precision degrades with reduced visual target contrast, or target changes over the observation time-lag. For instance, effects from bi-directional reflection distribution or, as an extreme case thereof, sun glitter may reduce matching precision (De Michele et al. 2012).

From all the above error influences together it becomes clear that best control over errors is achieved when sufficiently many and distributed non-moving objects are found in the scene for proper coregistration, and if the targets to be tracked move along a plane. In contrast, little error control is possible for isolated targets on an else contrast-free or unstable surface such as water. If no stable objects are present at all in the scene for co-registration, absolute geolocation errors add to the error budget.

\section{Application scenarios}

In this section we exemplify and discuss the above concepts using a range of application scenarios.

\subsection{River flow from ice debris}

Knowledge of water-surface velocities in rivers is useful for understanding a wide range of processes and systems. In cold regions, river-ice break up and the associated downstream transport of ice debris is often the most important hydrological event of the year, producing flood levels that typically exceed those for the open-water period and dramatic consequences for river infrastructure and ecology (Kääb and Prowse 2011).

Previous related studies investigated, for example: subtle river-ice deformation using radar interferometry (Smith 2002; Vincent et al. 2004); surface water flow from tracking foam, ice debris or thermal infrared features in ground-based or laboratory video-image sequences using particle image velocimetry techniques (Chickadel et al. 2011; Creutin et al. 2003; Ettema et al. 1997; Jasek et al. 2001; Puleo et al. 2012). River currents have also been derived using airborne and spaceborne along-track radar interferometry (Bjerklie et al. 2005; Romeiser et al. 2005; Romeiser et al. 2007; Romeiser et al. 2010; Siegmund et al. 2004).

Here we show examples exploiting the time-lag between pairs of along-track stereo imagery to track ice debris. Such ice debris is visible in high and medium resolution satellite images acquired during a certain time period after ice break-up and before freeze-up (Beltaos and Kääb 2014; Kääb et al. 2013; Kääb and Prowse 2011).

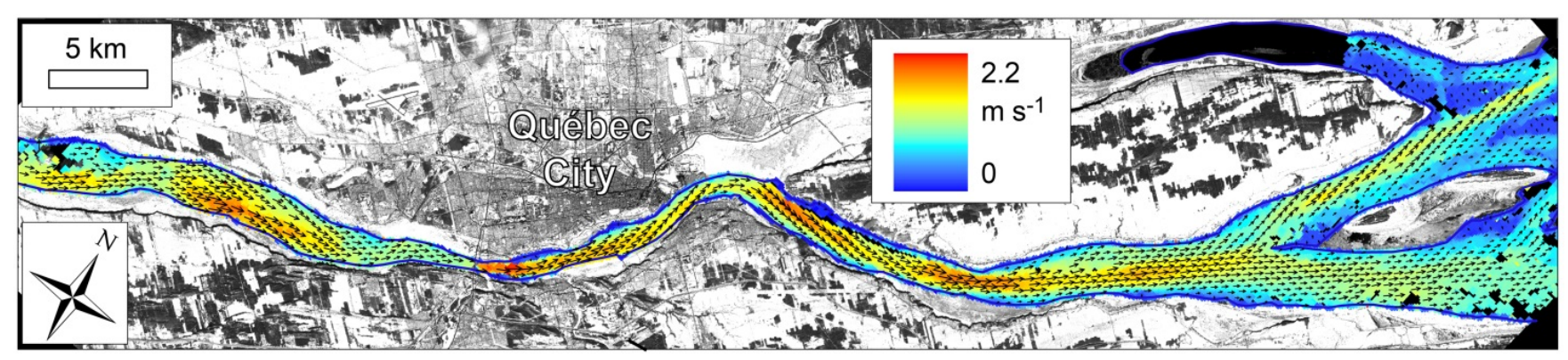

Fig. 5 Colour-coded surface flow velocities and vectors on the St. Lawrence River at Québec City, Canada, from an ASTER satellite stereo pair of 30 January 2003. The blue outline indicates the boundary of open water. Black data voids in the river and on the entire river branch to the upper right indicate open water without trackable ice debris. For better visibility, the velocity vectors, originally measured with $100 \mathrm{~m}$ spacing, have been resampled to $400 \mathrm{~m}$ spacing. Central latitude/longitude of the image $\sim 46.8^{\circ}-71.2^{\circ}$. 


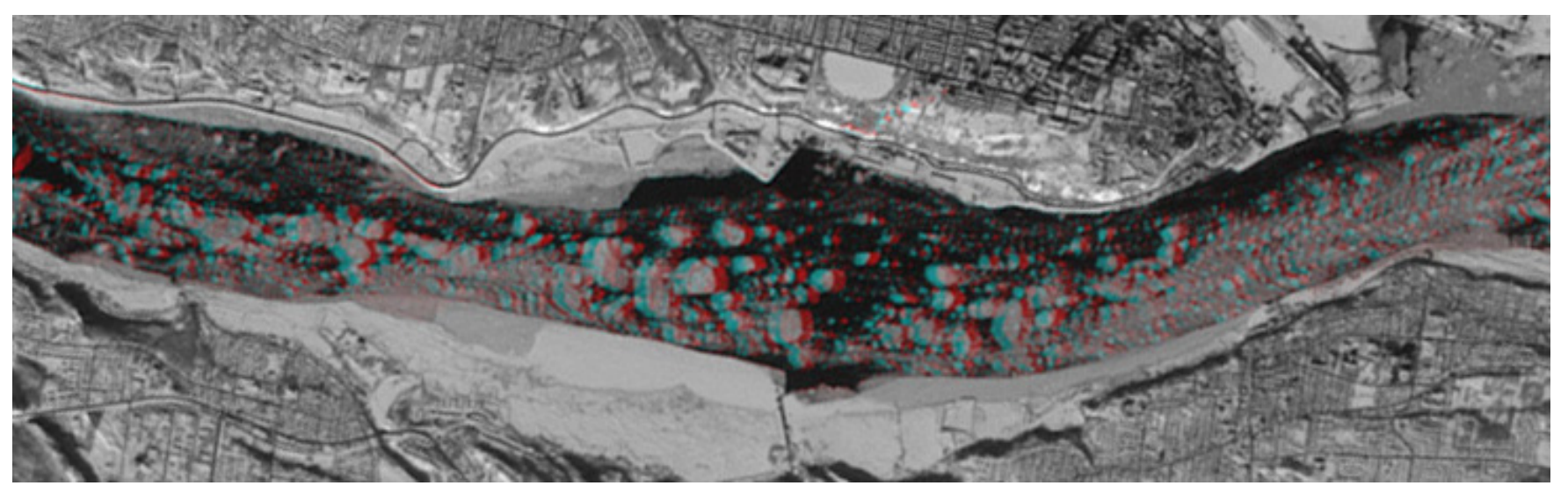

Fig. 6 Anaglyph combination of ASTER nadir and back-looking images over Québec City as used for Fig. 5. If viewed through red-cyan glasses, apparent elevations are proportional to the left-right component of water speed. Topographic distortions on the land have been removed.

For the St. Lawrence River at Québec City, we use a satellite stereo image pair from ASTER with $15 \mathrm{~m}$ ground resolution and $55 \mathrm{~s}$ time-lag (Fig. 2a, Fig. 5 and Fig. 6). The stereo images are co-registered using a first-order polynomial transformation based on stable objects at surface water level along the river margins. Ice debris is then tracked using NCC. Velocities are derived using image templates of $9 \times 9$ pixels in size $(135 \mathrm{~m} \times 135 \mathrm{~m})$ over a 100 -m spaced grid. In general, the ice floes are unconnected and are thus assumed to reflect uninterrupted surface flow. Maximum mid-channel floe velocities are up to $2.2 \mathrm{~m}$ $\mathrm{s}^{-1}$. Based on image correlation results for stranded and fast ice along the banks, we estimate an overall accuracy of $\sim \pm 0.25$ pixels $\left(3.8 \mathrm{~m}, 0.07 \mathrm{~m} \mathrm{~s}^{-1}\right)$ for the velocities from the ASTER data.

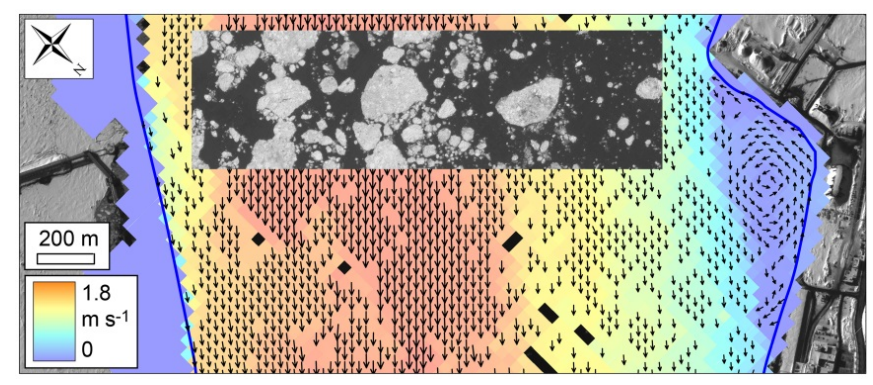

Fig. 7 Surface flow velocities and vectors on the St. Lawrence River at Québec City, derived from an Ikonos satellite stereo pair of 19 February 2000. Black data voids in the river indicate open water without ice debris tracked. All successfully measured velocity vectors are show $(25 \mathrm{~m}$ spacing). The matching results are removed over a rectangular section to the top to enable a view on the original Ikonos image.
For a $\sim 13 \mathrm{~km}$ sub-reach close to the center of Québec City, $1 \mathrm{~m}$ resolution Ikonos stereo data were acquired with $\sim 53 \mathrm{~s}$ time lapse (Fig. 7). Matches are obtained based on $25 \times 25$ pixel sized templates $(25 \mathrm{~m} \times 25 \mathrm{~m})$ over a $25 \mathrm{~m}$ regular grid. Again, the displacements of the unconnected ice floes and debris over the observation period are assumed to represent surface water velocities. In this case, comparison to stationary ice along the banks indicates an overall accuracy of $\sim$ \pm 0.7 pixels $\left(0.7 \mathrm{~m}, 0.01 \mathrm{~m} \mathrm{~s}^{-1}\right)$.

Landsat 7 and the Terra spacecraft, on which ASTER is mounted, share a similar orbit with Landsat 7 passing the equator roughly $30 \mathrm{~min}$ before Terra. For the above ASTER image pair of 30 January 2003 a Landsat image taken about $20 \mathrm{~min}$ before the ASTER data is available (Fig. 2g, Fig. A1, see Appendix). Tracking manually selected prominent ice floes between the Landsat 7 ETM+ pan and the ASTER nadir data gives average flow speeds that are not significantly different from the ones derived from the ASTER $55 \mathrm{~s}$ time-lag stereo data.

Surface velocities on a $40 \mathrm{~km}$ long reach of the Mackenzie River at Arctic Red River are measured based on a triplet stereo scene from the Panchromatic Remote-sensing Instrument for Stereo Mapping (PRISM) on board the Japanese ALOS satellite with $2.5 \mathrm{~m}$ ground resolution and $45 \mathrm{~s}$ or $90 \mathrm{~s}$ time-lags, respectively (Fig. 2c and Fig. 8). The forward and backward images are co-registered to the nadir image. Surface velocities are measured using $20 \times 20$ pixel sized templates $(50 \mathrm{~m} \times 50 \mathrm{~m})$ over a $50 \mathrm{~m}$ grid. Maximum surface velocities are up to around $2 \mathrm{~m} \mathrm{~s}^{-1}$. In contrast to the data over the St. Lawrence River, the 
Kääb A. and Leprince S. (2014): Motion detection using near-simultaneous satellite acquisitions.

Remote Sensing of Environment, 154, 164-179. DOI: 10.1016/j.rse.2014.08.015 (Initial manuscript version).

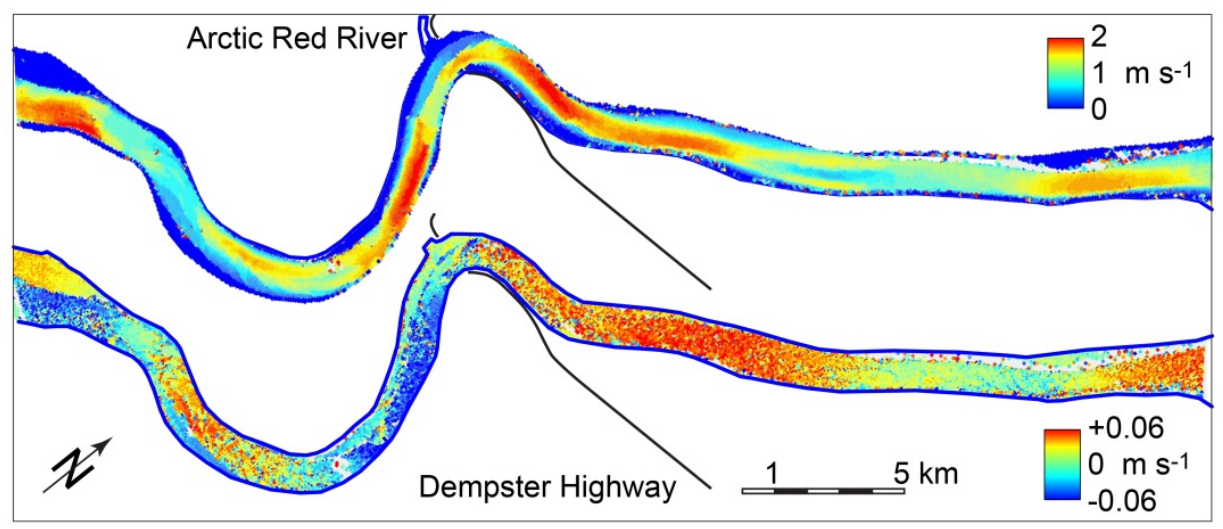

Fig. $8 \quad$ Upper: Ice speeds on the Mackenzie River at Arctic Red River on 20 May 2010 using PRISM stereo data with 45 s time-lag. Lower: PRISM has three stereo channels (Fig. 2c). The lower panel shows the difference between the forward-nadir 45-s speeds and the nadir-backward 45-s speeds. Central latitude/longitude $\sim 67.5^{\circ} /-133.9^{\circ}$.

images over the Mackenzie River were taken during an ice run, and the ice floes are in parts densely packed so that the velocities shown represent in some areas water velocities, but in other areas rather the dynamics of the ice run with considerable lateral effects on the ice-floe motion (Beltaos and Kääb 2014). From stationary shore ice we estimate a standard deviation for the 45-s displacements of \pm 0.5 pixels $\left(1.3 \mathrm{~m}, 0.03 \mathrm{~m} \mathrm{~s}^{-1}\right)$.

From the PRISM data over Mackenzie River at Arctic Red River, displacements are tracked in the forwardnadir (45 s), the nadir-backward (45 s), and the forward-backward pair (90 s). Displacements of the 90 $\mathrm{s}$ forward-backward interval turned out to be more prone to gross errors due to stronger changes of the ice-debris pattern matched over the longer time-lag. The differences between the speeds from the two $45 \mathrm{~s}$ combinations depict the measurement noise but also show a clear pattern of reaches with ice-debris speeds accelerating and decelerating over the $90 \mathrm{~s}$ observed, suggesting pulses within the ice run (Fig. 8). Comparison to shore ice confirms that this signal is only little contaminated by co-registration errors.

In a further test employing near-simultaneous airborne imagery instead of satellite data, ice debris was tracked on the Yukon River at Eagle, Alaska, in the overlap area of two consecutive nadir frame images of an airphoto flight (Fig. A2, Appendix). The maximum displacement over the $\sim 6 \mathrm{~s}$ time-lag translate to $\sim 2.7 \mathrm{~m}$ $\mathrm{s}^{-1}$ maximum water velocity.

Stereo data from ASTER, PRISM, and very-highresolution data such as Ikonos, Quickbird and
WorldView were also tested successfully over a number of other rivers with ice debris, both under breakup and freeze-up conditions, and in addition also Corona-series stereo acquisitions and nearsimultaneous astronaut photos taken from Space Shuttles or the International Space Station (Fig. A3, Appendix).

In general, ice debris on rivers represents an almost perfect target type for our method. Image matching appears robust as the bright and well defined ice floes on the dark and contrast-free water surface are perfect features. In most cases, it will be possible to approximate entire reaches of large rivers as planes, which simplifies co-registration of the stereo images. Area-wide quantification of ice fluxes and water velocities holds a large, so far unexploited potential to better understanding of river processes and discharge, and to supporting related engineering applications.

\subsection{Water velocities from suspended sediments}

In contrast to ice debris, it will in most cases be less certain to which extent moving sediment plumes (Matthews 2005), or short-wave infrared and thermal infrared contrasts (Chickadel et al. 2011) on the water surface correspond to water surface velocities. Rather, in addition to pure advection, the motion of such features also involves mixing processes (Chickadel et al. 2011).

In Fig. 9 we demonstrate the velocity of sediment features from airphotos over the inlet of the Tennessee river into the Ohio river at Paducah, Kentucky, USA. The two overlapping airphotos used were taken with a 


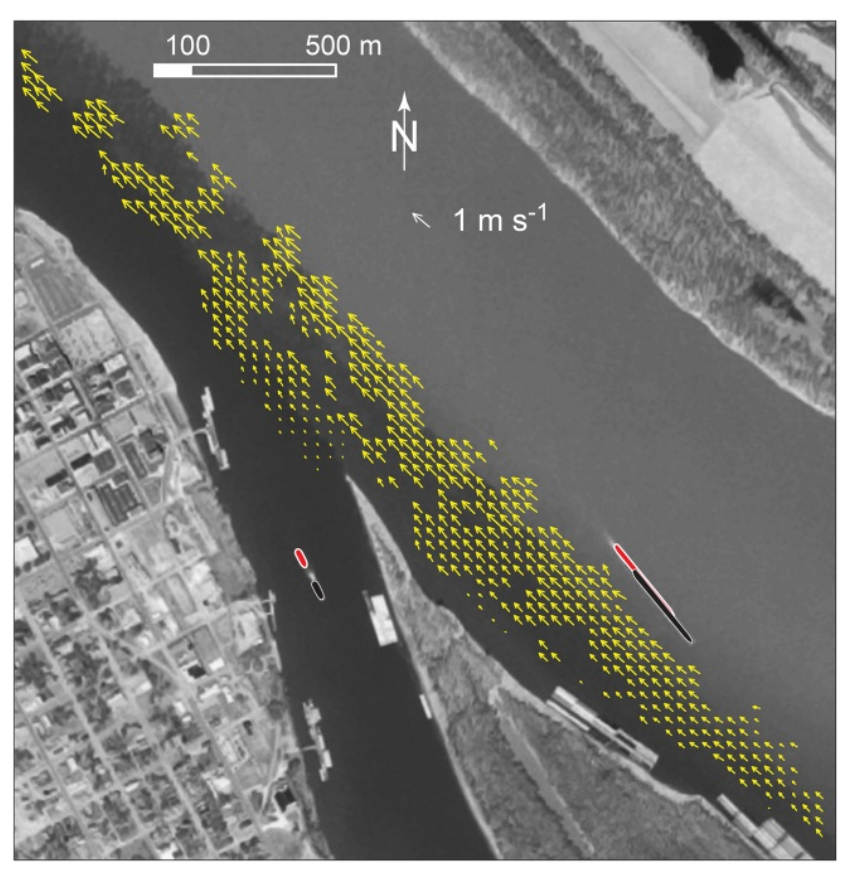

Fig. 9 Suspended sediment velocities at the inlet of the Tennessee River (left) into the Ohio river (right) at Paducah, Kentucky, USA. Typical sediment features tracked are visible to the upper left where some vectors have been removed for this purpose. Tracking failed else where no vectors are shown, mostly due to the lack of visible sediment features and effects of bidirectional reflection. The two overlapping airphotos used were taken under the USGS-coordinated National Aerial Photography Program (NAPP) on 17 March 2005 with a 230 s time-lag. The two red-black object pairs are boats in both of the images. Central latitude/longitude $\sim 37.1 \%-88.6^{\circ}$.

$\sim 30$ s time-lag. A central nadir section of one image was selected for the study and the second image coregistered so that perspective distortions in the master image are minimized but not completely eliminated. Displacements were matched using NCC with $30 \mathrm{~m} \times$
$30 \mathrm{~m}$ template size, resulting in maximum speeds of about $1 \mathrm{~m} \mathrm{~s}^{-1}$ over the river reach studied.

In order to investigate suspended sediment motion from space imagery, sediment features were also tracked based on an ASTER stereo scene at the confluence of the Amazon River and the Rio Negro at Manaus, Brazil (Fig. 10). The $55 \mathrm{~s}$ time-lag between the stereo images revealed speeds of up to $1.8 \mathrm{~m} \mathrm{~s}^{-1}$ for the few, though, successful matches. Image matching was considerably complicated by sun-glitter in the nadir scene (De Michele et al. 2012; Matthews 2005; Matthews and Awaji 2010).

In contrast to tracking river ice debris in nearsimultaneous imagery, tracking sediment features is restricted to small areas as suitable features are typically found only over shorter distances before mixing processes dilute them. Also, such sediment features represent less sharp contrasts and their matching over time is thus less reliable. On the other hand, suitable sediment features will in many cases not be limited to short periods of the year, such as for river ice debris, but potentially be available for yearround observations. Measuring displacements of sediment features at river confluences (shown here) or river mouths (not shown here) could give insights into water flow, and sediment transport and mixing processes at such locations. Other water surface features that can potentially be tracked within nearsimultaneous images are floating matter or disturbances of sun glitter such as from oil films. Using 45-90s time-lag PRISM data, Matthews and Awaji (2010) demonstrate sea surface vectors from surface films that modify or reduce sun glitter, such as from boat wakes, natural oil seepage, or enhanced biological activity. Figure A4 (Appendix) shows the velocity field of an algae bloom from a sequence of EO-1, Landsat and ASTER data.

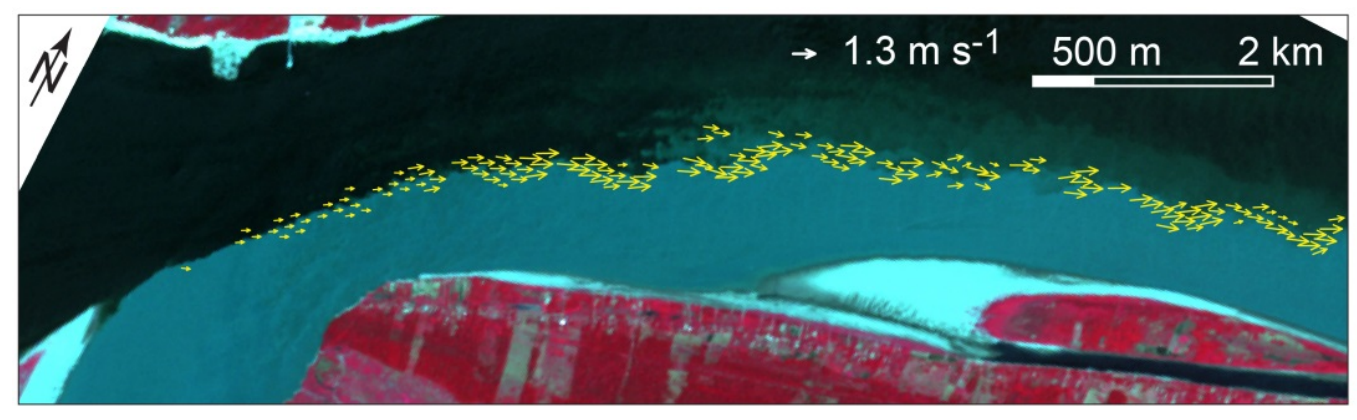

Fig. 10 Confluence of Amazonas (lower) and Rio Negro (upper) at Manaus, Brazil. Displacement vectors of sediment plumes from an ASTER stereo scene of 30 Sept 2010 with 55 s time-lag. Central latitude/longitude -3.1\%-59.9 . 


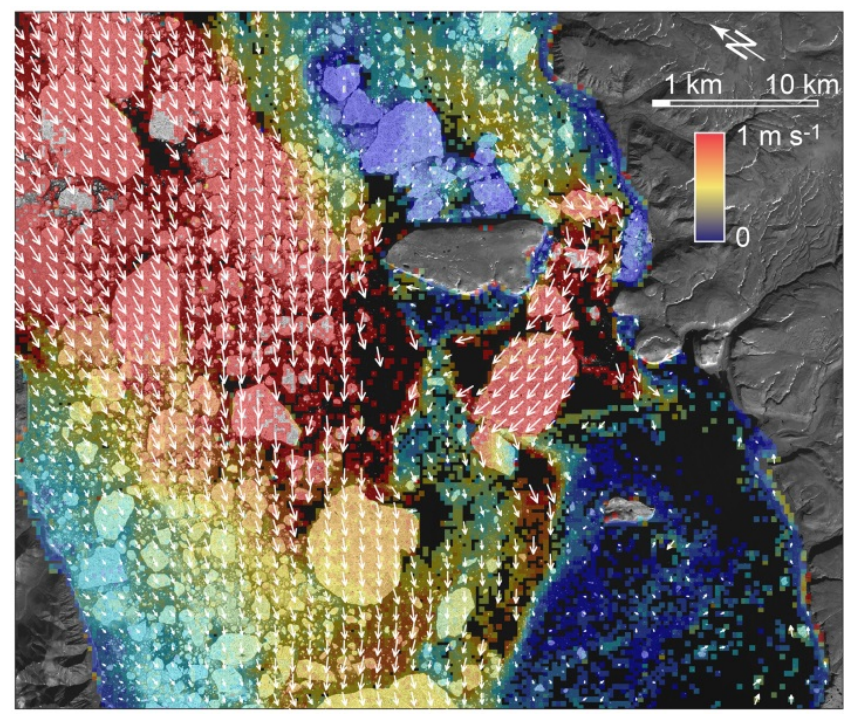

Fig. 11 Kennedy Channel, Nares Strait, between Greenland (right) and Canada (left). Sea ice motion is tracked using an ASTER stereo pair of 22 July 2007 with 55 s timelag. Speeds are colour-coded and superimposed over the satellite image. Vectors have been resampled from the original vector grid of $250 \mathrm{~m}$ to $1 \mathrm{~km}$ spacing. Central latitude/longitude $\sim 80.6 \%-67.2^{\circ}$.

\subsection{Sea ice}

Similar to river ice, sea ice can be tracked in nearsimultaneous images, for instance to display tidal currents. Here, we explore three different nearsimultaneous images and acquisition types.

Sea ice motion is tracked over the Kennedy Channel of the Nares Strait between Greenland and the Canadian Ellesmere Island using an ASTER stereo pair with $55 \mathrm{~s}$ time-lag and $15 \mathrm{~m}$ resolution (Fig. 11). Maximum ice floe speeds reach almost $1 \mathrm{~m} \mathrm{~s}^{-1}$. The velocity field exhibits a complex motion pattern, influenced by islands and interaction between ice floes. It is unclear to which extent the observed ice velocities reflect water velocities from the general sea water flux and tides through the channel (Munchow and Melling 2008; Rabe et al. 2010), or how far they are also influenced by wind and ice floe interaction.

A WorldView-2 stereo pair with $0.5 \mathrm{~m}$ ground resolution and with $74 \mathrm{~s}$ time-lag over the Knik Arm of the Cook Inlet at Anchorage, Alaska, shows fine ice debris moved by the falling tidal stream. Matching reveals ice debris speeds of up to $2.7 \mathrm{~m} \mathrm{~s}^{-1}$ and more (Fig. 12). Clearly, the NCC used has problems and fails where horizontal eddies, for instance at the narrowest part of the Knik Arm (inset), cause strong

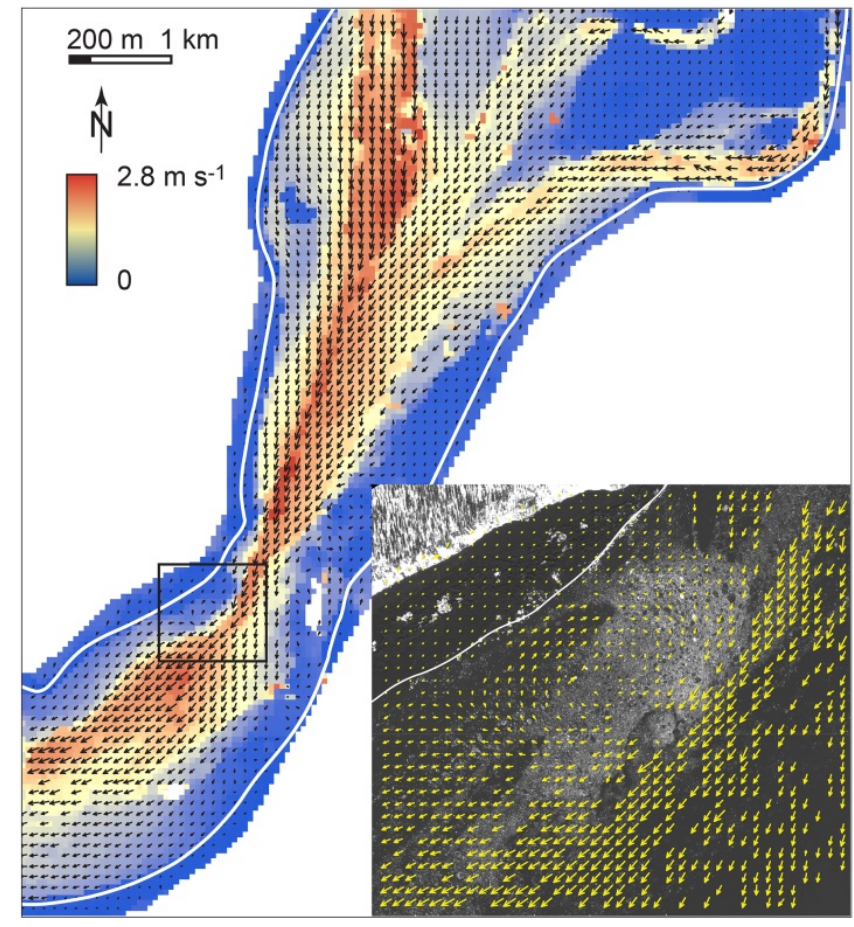

Fig. 12 Knik Arm, Anchorage, USA. Water surface velocities from fine ice debris tracked over 74 s time-lag between in-track stereo acquisitions of WorldView-2 from 17 March 2010. The inset to the lower right shows the detail of an eddy (location: black rectangle in the main panel). Central latitude/longitude $\sim 61.3^{\circ} / 149.9^{\circ}$.

rotations over the $74 \mathrm{~s}$ time-lag available. Also, the large displacements of up to $200 \mathrm{~m}$ over the $74 \mathrm{~s}$ in relation to the high image resolution of $0.5 \mathrm{~m}$, i.e. 400 pixels displacement, require large search window sizes bearing a large probability of ambiguous matches. The number of successful matches was here substantially increased by employing an image pyramid approach, first matching displacements in a 2 m-resolution version of the images and using these results then as initial values for matching the full resolution images. The software used here for matching, CIAS (Kääb 2013), has a built-in two-layer image pyramid option.

In front of the Amery Ice Shelf, East Antarctica, frazil ice and some icebergs were imaged by the Advanced Land Imager (ALI) onboard the EO-1 spacecraft and $400 \mathrm{~s}(6.6 \mathrm{~min}$ ) later by Landsat7 ETM+ (Fig. 2g, Fig. 13). The image section of concern was in the middle of the Landsat image so that the ETM+ SLC-off data voids did not affect the measurements. After coregistration along the ice shelf front, matching of the two images shows speeds of up to $0.8 \mathrm{~m} \mathrm{~s}^{-1}$ for the frazil ice, whereas the speed of the icebergs is not 


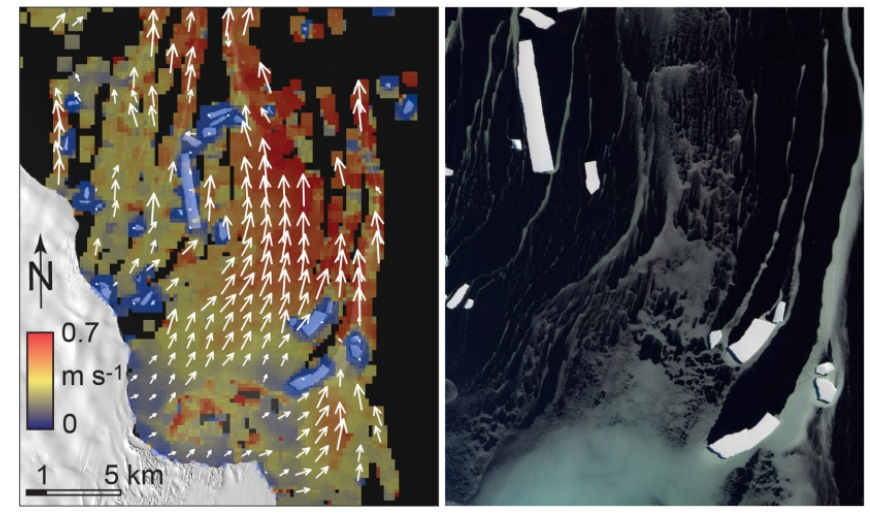

Fig. 13 Amery lce shelf, Antarctica. Frazil ice and ice bergs (see detail to the right) were tracked between images from the Advanced Land Imager (ALI) onboard the EO-1 spacecraft and Landsat 7 ETM+ on 12 Feb 2012 and with $400 \mathrm{~s}$ (6.6 minutes) time-lag. Vectors on the left panel are resampled from a $200 \mathrm{~m}$ to a $1 \mathrm{~km}$ grid. Central latitude/longitude $\sim-68.4^{\circ} / 70.2^{\circ}$.

distinguishable from zero. This difference suggests that the frazil ice moves mainly due to wind blowing off the ice shelf, not water currents.

As tracking sea ice motion from repeat optical and radar images with time-lags on the order of days is already a standard technique (e.g., Emery et al. 1997; Lavergne et al. 2010; Wohlleben et al. 2013), using time-lags of seconds to minutes adds mainly to understanding of geophysical processes related to, for instance, interaction of sea ice floes with each other or with land, and with wind. Also, the technique could be useful to investigate short-term variations of sea ice motion, within the operational sea-ice motion products typically derived for longer time intervals from observations or models. As for river ice, sea ice floes appear to be near-perfect targets for image matching due to their contrast, form and distribution on a dark planar surface with an altitude similar to the satellite reference ellipsoid.

\subsection{Cloud motion}

Cloud motion and cloud wind speeds over large areas are standard products from repeat geostationary meteorological satellites (e.g., Genkova et al. 1999), but also from multi-angular data of the MISR sensor aboard the Terra spacecraft (Horvath and Davies 2001). Data over smaller areas but with higher spatial resolution can in particular be used for calibrating or validating results using imagery with coarser resolution. Cloud motion has to our best knowledge rarely been derived from high and very high resolution

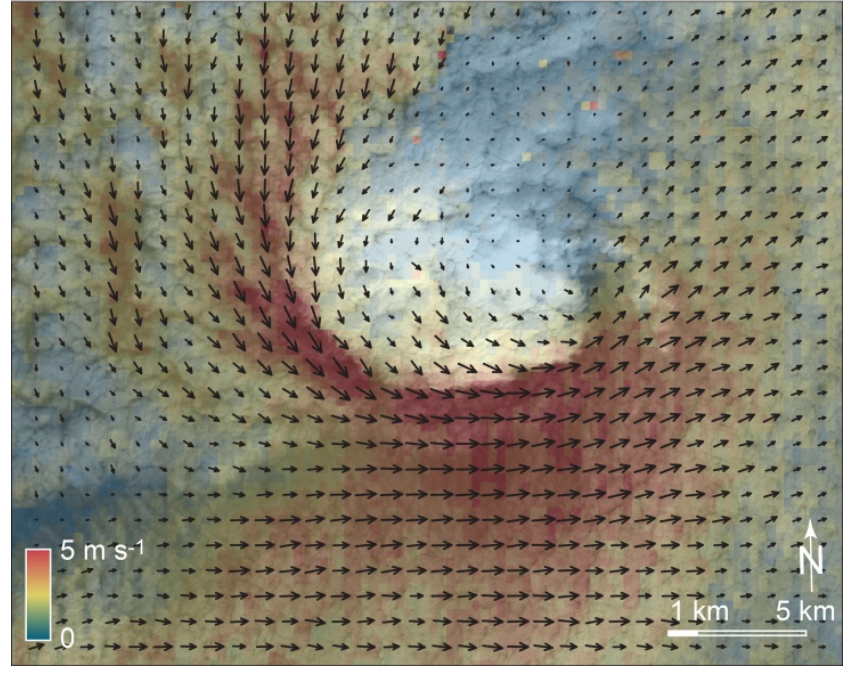

Fig. 14 Velocity vectors on a cloud vortex north of Unimak Island, Aleutian Islands, Alaska, derived from an ASTER stereo pair of 7 Sept 2010. Vectors shown are resampled from a $300 \mathrm{~m}$ grid (colour-coded speeds) to a $900 \mathrm{~m}$ grid. Central latitude/longitude $\sim 55.5^{\circ}-164.5^{\circ}$.

near-simultaneous data (Seiz et al. 2003). The major difficulties thereby are the unknown overall absolute elevation of the cloud level, the upper cloud topography, and, typically, the lack of stable land points for image co-registration. The latter problem requires accepting the spacecraft derived image geolocation and including its accuracy in the error budget of the motion measurement. Alternatively, relative motions can be investigated after an overall co-registration, and such relative motion can be nested in coarser motion patterns, e.g., from geostationary satellites or MISR (Seiz et al. 2003).

Here, we show cloud velocities over a random vortex north of Unimak Island, Aleutian Islands, Alaska, derived from an ASTER stereo pair (Fig. 14). The two images are co-registered using a land point at cloud level on a mountain extending through the clouds (not contained in the image section shown). Though, effects on the displacements from overall cloud height and cloud topography are to be expected. Under these limitations, maximum cloud speed observed is up to 5 $\mathrm{m} \mathrm{s}^{-1}$. For the matching, image templates of $40 \times 40$ pixels $(600 \mathrm{~m} \times 600 \mathrm{~m})$ were used. For this example NCC gives only few reasonable matches (not shown), while $\mathrm{CCO}$ gives the cloud motion field shown in Fig. 14 , with reasonable matches for almost all grid points. This underlines the finding by Heid and Kääb (2012) that $\mathrm{CCO}$ is particularly advantageous for images with diffuse visual contrast. 


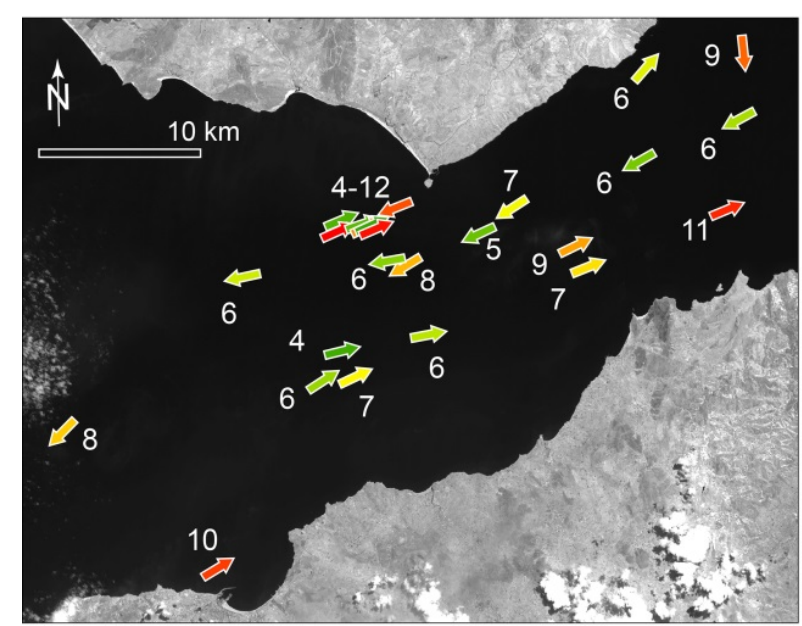

Fig. 15 ASTER-derived ship motion over the Strait of Gibraltar between Spain (top) and Morocco (bottom). Maximum speeds $12 \mathrm{~m} \mathrm{~s}^{-1}$ (23 knots). Central latitude/longitude $\sim 35.9 \%-5.6^{\circ}$.

\subsection{Vehicles from minute-scale time-lags}

Vehicles can be tracked within the time-lag of tens to hundreds of seconds between spaceborne along-track stereo data. Whereas ships can be easily identified and thus tracked in the repeat images due to their comparable low speed and stable direction, tracking cars requires to clearly identify individual vehicles over distances of several hundred meters or more. This is usually only possible when using very-high resolution images.

In that respect, tracking cars is simplified using airborne along-track stereo (or even video), which typically has much smaller time-lags and higher spatial resolution (Reinartz et al. 2006). Spaceborne time-lags of minutes have seldom been used for vehicle motion (Matthews 2005; Takasaki et al. 1993). However, even if ships appear near-perfect targets for such tracking, their matching can be complicated by differences in sun glitter present in the stereo images (Matthews 2005; Matthews and Awaji 2010). Ship detection can be supported by thermal infrared bands, if available, such as for ASTER (Matthews 2005), where ship wakes also cause thermal anomalies.

Our example of Fig. 15 shows ship motion of up to 12 $\mathrm{m} \mathrm{s}^{-1}$ (23 knots) over the Strait of Gibraltar on 21 May 2001 during a 55s time-lag between ASTER stereo images. Results by using CCO seem to be slightly more robust than those from NCC, presumably due to reduced effect of sun glitter that was especially present in the nadir image (ASTER band $3 \mathrm{~N}$ ).

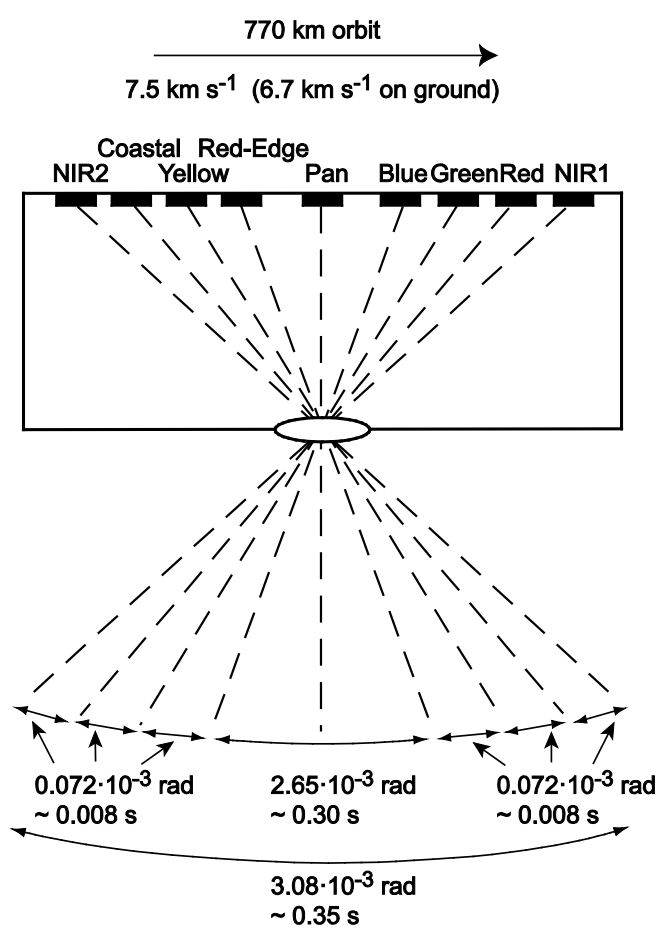

Fig. 16 Schematic drawing of the WorldView-2 focal plane with the angles and time-lags associated with along-track offsets of detector lines in the focal plane.

\subsection{Vehicles from second-scale time-lags}

In multispectral pushbroom sensors that avoid beam splitters within their optical system to divert incoming light into spectral sections, individual detector lines for different bands need to have a slightly different view direction (Fig. 2k, Fig. 16). While this effect is largely unwanted because it causes small parallaxes between the bands depending on terrain height (May and Latry 2009), such constellation with very small angles leads to time-lags of few milliseconds to few seconds, depending on the sensor construction and the choice of bands. As a consequence, motion of vehicles that move fast enough to cause displacement of at least a considerable fraction of the sensor's groundprojected pixel size, such as cars, trains and airplanes, can be visualized and measured. Such spaceborne time-lags have seldom be used for vehicle motion (Pesaresi et al. 2008). Other work focuses rather on along-track radar interferometry for vehicle motion (Himed and Soumekh 2006; Palubinskas et al. 2007).

As an example, the WorldView-2 (WV-2) focal plane is structured to have four multispectral bands, then the pan band, then the other four multispectral bands (Fig. 16). The band order is Near-infrared 2 (NIR2), 


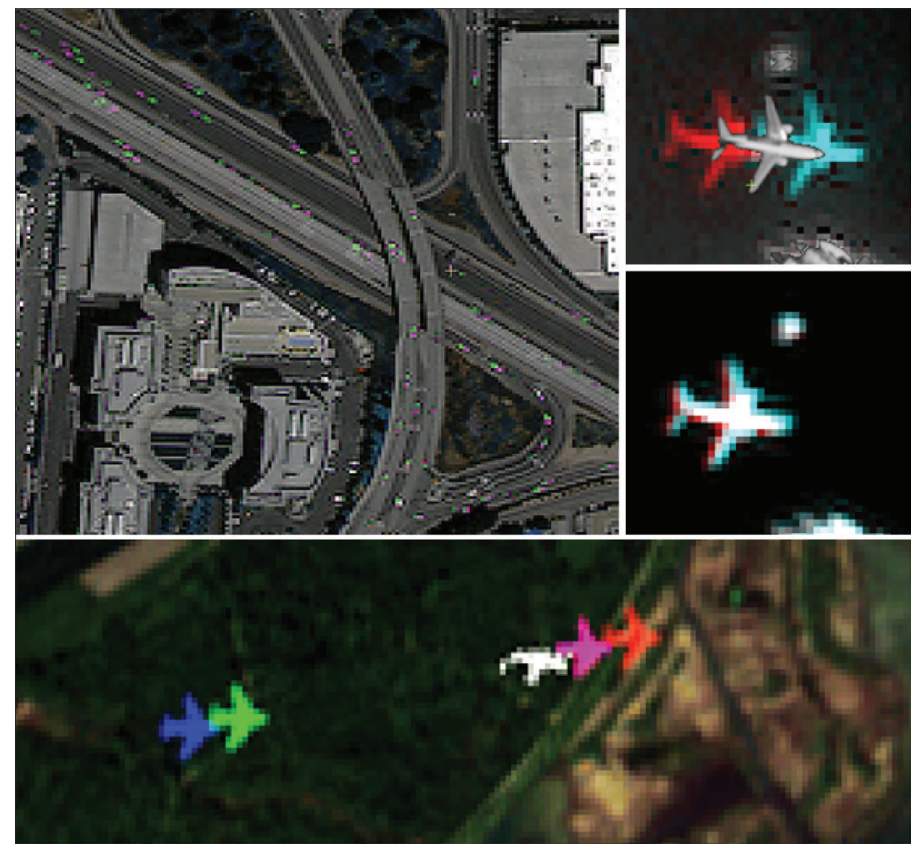

Fig. 17 Moving vehicles in pushbroom images with along-track detector offsets. Upper left: Red-Edge/Red/Yellow R/G/B composite of a section of a WorldView-2 image over Palo Alto, California, USA.. The green-magenta object pairs are cars moving over the $\sim 0.35 \mathrm{~s}$ time-lag between the acquisitions of the bands. Right: Airplane in an WorldView-2 image, NIR1/NIR2/NIR2 R/G/B composite with pan channel superimposed (upper right; maximum time-lag $\sim 0.35 \mathrm{~s}$ ), and blue/green/green R/G/B composite (lower right; time-lag $\sim 0.008 \mathrm{~s}$ ). Lower: Airplane in all 5 bands of a RapidEye image with $6.5 \mathrm{~m}$ resolution with incremental time-lags from left to right $0.33 \mathrm{~s}, 2.0 \mathrm{~s}, 0.33 \mathrm{~s}, 0.33 \mathrm{~s}$, in total $3 \mathrm{~s}$.

Coastal, Yellow, Red-Edge (all four here abbreviated as NCYR), then the pan band, then Blue, Green, Red, NIR1 (all four: BGRN). Between each successive colour in this sequence there is a 72 microradians angle except that between Red-Edge and Blue of about 2.65 milliradians (personal communication, Kumar Navulur, DigitalGlobe). These angular differences translate into time lags between the bands of $\sim 0.008 \mathrm{~s}$, and $\sim 0.30 \mathrm{~s}$, respectively, with a total maximum timelag of $\sim 0.35 \mathrm{~s}$ between the NIR2 and NIR1 bands. Other corresponding constellations include QuickBird with a time lag of $\sim 0.2 \mathrm{~s}$ between the pan and multispectral sensors, Spot5 HRG with a maximum time lapse of $\sim 2 \mathrm{~s}$, or RapidEye with $\sim 3 \mathrm{~s}$ (De Michele et al. 2012; May and Latry 2009; Pesaresi et al. 2008).

In the spectral domain, such as in colour composites, movement of fast targets results in a colour shift along the object's movement axis (Fig. 17). The size and spectral composition of this colour offset (or frame or halo) at the snout and tail of the object, or the offset of complete duplicates of entire vehicles in case of faster or small vehicles, is directly related to the speed of the object. For particularly fast vehicles, e.g. airplanes, also composites within BGRN or NCYR bands, i.e. nearby bands, show colour frames due to movement (Fig. 17).

In Fig. 18 we show car speeds on a highway in Palo Alto, USA, from the NIR1 and NIR2 bands of a WV-2 image of 1 May 2010 and a time-lag of 0.35 s. Vehicle displacements were derived by manually selecting cars in one image, and matching them in the other image using templates of $3 \times 3$ to $5 \times 5$ pixels. From matching parked cars we estimate a speed accuracy of $\sim \pm 1 \mathrm{~m} \mathrm{~s}$ 1 .

For along-track (also called in-track) stereo acquisitions of sensors such as WV-2, the stereo timelag of many seconds to minutes described in section 4.5 and the smaller time-lag between bands as described here can be combined by measuring the speeds of slow vehicles from the longer time-lag, and the one of faster vehicles separately in all multispectral stereo images. Knowing the speed of individual vehicles from inter-band time-lags helps identifying the same vehicles in stereo images, so that both their average speed over the stereo time-lag can be estimated and the actual velocity at the times of the stereo acquisitions using the inter-band time-lag. Eventually, velocity magnitudes and directions can be 


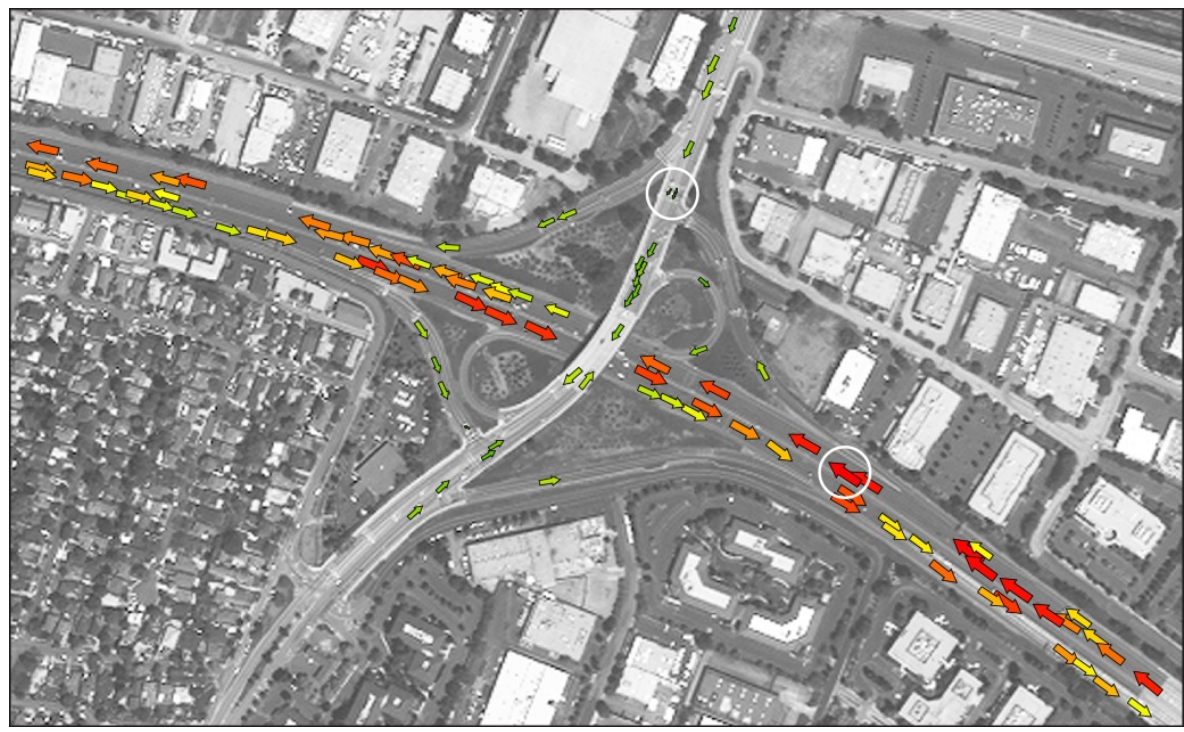

Fig. 18 Highway in Palo Alto, USA, from WorldView-2. Car velocity with colour-coded vectors according to the car speed. Dark green, upper white circle: cars waiting at traffic light $\left(0 \pm 1 \mathrm{~m} \mathrm{~s}^{-1}\right)$. Red, right white circle: maximum car speeds of $37 \mathrm{~m} \mathrm{~s}{ }^{-1}$ $\left(130 \mathrm{~km} \mathrm{~h}^{-1}, 82 \mathrm{mph}\right)$.

measured for a large number of vehicles over large scales for two or more points in time together with the average vehicle speed over this $\sim 1-2$ minute period. These possibilities open new perspectives for among others traffic management and related research. We

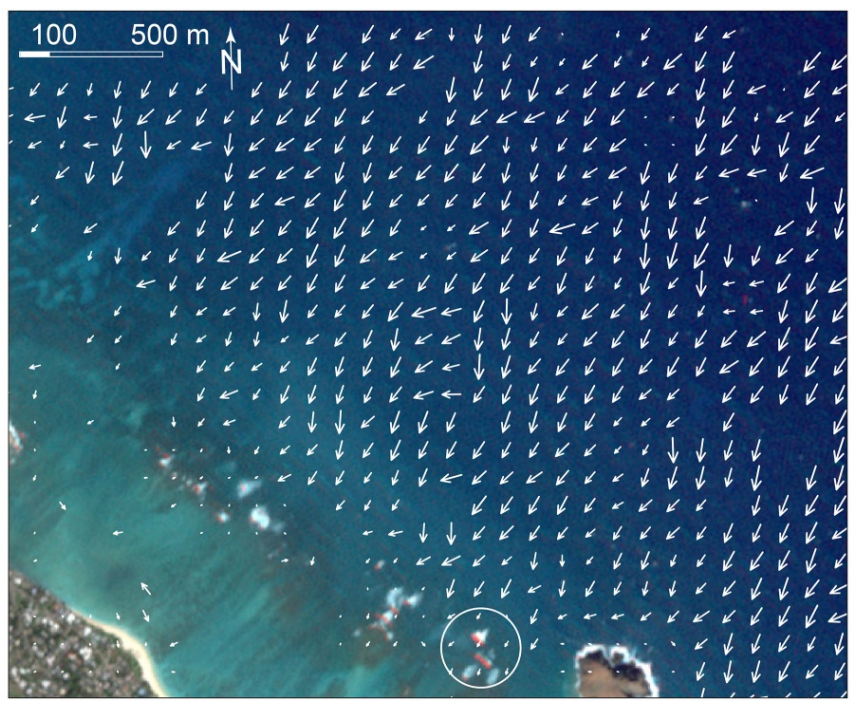

Fig. 19 Phase velocities of ocean waves at O-ahu, Hawaii, USA, from band offsets in a 5 December 2010 RapidEye image. Maximum speeds $\sim 9 \mathrm{~m} \mathrm{~s}^{-1}$. The white circle to the bottom marks colour-halos from breaking waves between the bands of the colour composite. Vectors with a correlation coefficient smaller than 0.2 have been removed. Central latitude/longitude $\sim 21.4 \%-157.7^{\circ}$. tested the methodology successfully for road vehicles, trains, boats and airplanes.

\subsection{Wave motion}

Matthews (2005) discusses the appearance of waves in near-simultaneous ASTER imagery (Fig. 2a). Matthews and Awaji (2010) use the 45-90 s time-lags between PRISM data (Fig. 2c) to investigate ocean waves and currents. De Michele et al. (2012) use a time-lag of $\sim 2 \mathrm{~s}$ from detector line offsets on the SPOT5 HRG focal plane (constellation principle Fig. $2 \mathrm{k}$ in this contribution) to measure the phase velocity of ocean waves. Here, we demonstrate phase velocities of ocean waves from the $3 \mathrm{~s}$ time-lag between the blue and red bands of a 5 December 2010 RapidEye scene over O'ahu, Hawaii, USA (Fig. 19). Displacements have been matched with templates of $40 \times 40$ pixels $(260 \mathrm{~m} \times 260 \mathrm{~m})$. While matching works reasonably well, it gets confused as soon as the sea bed becomes visible through the water column at shallow zones.

Also the longer time-lag from stereo acquisitions was used to explore waves. The run-up of the 26 December 2004 Tsunami in the Indian Ocean has been captured in different bands of the MISR instrument (Fig. 2e) (Garay and Diner 2007). 
Kääb A. and Leprince S. (2014): Motion detection using near-simultaneous satellite acquisitions.

Remote Sensing of Environment, 154, 164-179. DOI: 10.1016/j.rse.2014.08.015 (Initial manuscript version).

\section{Conclusions and Perspectives}

Our overview shows a large but so far hardly exploited potential to detect and measure motion from near-simultaneous airborne and spaceborne images, and gives a non-exhaustive set of case studies. Two main constellation principles of angular time-lags are used; (i) stereo acquisitions with typical time-lags on the order of a minute, and (ii) much smaller time-lags, a few seconds or less, associated with along-track offsets of detector lines in the focal plane of pushbroom systems. The magnitude of motion that can in principle be investigated this way depends on the time-lag and the ground resolution of the image. For example, a typical steered in-track stereo acquisition by very-high resolution sensors such as Pleiades or WorldView-2 covers time-lags of up to about 4 minutes. The corresponding image resolution is up to $0.5 \mathrm{~m}$ (and potentially smaller in the near future with relaxed legal restrictions). Assuming tracking accuracies of at least one pixel (depending on the target type sub-pixel accuracy can be achieved, though) gives a minimum speed of about $0.002 \mathrm{~m} \mathrm{~s}^{-1}$ $\left(7 \mathrm{~m} \mathrm{~h}^{-1}\right)$ that can be detected. Minimum detectable motion using the $2.5 \mathrm{~m}$ resolution PRISM sensor, for instance, with a time-lag of up to $90 \mathrm{~s}$ is about $0.03 \mathrm{~m}$ $\mathrm{s}^{-1}\left(100 \mathrm{~m} \mathrm{~h}^{-1}\right)$, and for the $15 \mathrm{~m}^{-1}$ resolution ASTER with $55 \mathrm{~s}$ time-lag $0.3 \mathrm{~m} \mathrm{~s}^{-1}\left(1 \mathrm{~km} \mathrm{~h}^{-1}\right)$.

A range of natural and man-made targets reach speeds higher than the above examples, for instance matter floating on and in rivers, lakes and oceans, driven by currents and wind, lava streams, clouds, and most vehicles. Whether motion of such targets can actually be detected, however, equally depends on the visual preservation of targets over the observation time-lag, and on the possibility to unambiguously identify the corresponding target in two or more near-simultaneous images. This condition can be difficult to fulfil for some target types, e.g. waves. As for all optical spacebased methods, the application of the method to space imagery is in most cases (with the exception of cloud motion) restricted for use with cloud-free day-time data.

The second constellation principle for nearsimultaneous acquisitions, resulting from focal plane set-up or near parallel individual sensors for different bands or band-groups, requires much faster motions to be detectable. For RapidEye imagery (time lag up to 3 $\mathrm{s} ; 6.5 \mathrm{~m}$ resolution) or SPOT5 HRG imagery (up to $2 \mathrm{~s}$ between pan and multispectral; $5 \mathrm{~m}$ or $10 \mathrm{~m}$ resolution, respectively), for instance, minimum detectable target motion at pixel level is on the order of 2-5 ms ${ }^{-1}$ (7-18 $\mathrm{km} \mathrm{h}^{-1}$ ). For time-lags of up to $0.3 \mathrm{~s}$ and a ground resolution of $2 \mathrm{~m}$, such as for WorldView-2, the respective values are on the same order of magnitude, $8 \mathrm{~m} \mathrm{~s}^{-1}\left(30 \mathrm{~km} \mathrm{~h}^{-1}\right)$. These limits make the motion detection mostly feasible for vehicles such as cars, trains and airplanes, or fast natural motions such as waves, in particular if matching at sub-pixel accuracy is possible. Tracking motion from even shorter timelags, such as $0.008 \mathrm{~s}$ for focal-plane band-neighbours of WV-2 pushes the minimum detectable target speed to several $100 \mathrm{~km} \mathrm{~h}^{-1}$, i.e. airplane speed.

Time-lags such as from satellites following each other on similar orbits ('trains') were not the main focus of this study, and only demonstrated shortly for completeness. Minimum detectable motion at pixel level will be on the order of $0.01 \mathrm{~m} \mathrm{~s}^{-1}$ (few $10 \mathrm{~m} \mathrm{~h}^{-1}$ ) for imagery of 15-30 m resolution (e.g. Landsat ASTER, Landsat - EO-1 ALI).

For most near-simultaneous acquisition constellations covered in this overview, target height cannot be determined together with target velocity. Whereas target height is at least approximately known for a number of applications (e.g., on the ocean or big lakes) or can be solved by co-registration where motion takes place along a planar surface with stable elements visible (e.g., lake or river shore lines, or roads), this will impose a limitation for some other applications (e.g., clouds or airplanes).

Our study presents an initial evaluation and systematic overview of the methodology for deriving motion from angular near-simultaneous airborne and spaceborne imagery. A number of improvements can easily be implemented to increase the degree of automation and accuracy of the velocity measurements towards more operational procedures. For instance, geometric constraints can be introduced (Meng and Kerekes 2012). Also, we used only two common matching algorithms, and compared not systematically which of these give better results and under which circumstances. Our comparison for cloud motion, however, where orientation correlation (CCO) clearly showed better performance than normalized crosscorrelation (NCC), highlights that it might be worth to better investigate different matching algorithms for the purpose of motion detection from near-simultaneous imagery. Both algorithms used here did not allow for template rotation, which appeared to be a significant 
Kääb A. and Leprince S. (2014): Motion detection using near-simultaneous satellite acquisitions.

Remote Sensing of Environment, 154, 164-179. DOI: 10.1016/j.rse.2014.08.015 (Initial manuscript version).

limitation for instance for ice debris in water eddies, and calls for tests using least-square matching (Debella-Gilo and Kääb 2012).

The results demonstrated in this contribution were only possible because of the fortuitous availability of archived satellite and airphoto records, which currently contain limited and short intervals of relevant data for some of the phenomena investigated, such as river ice, but plenty for others, such as clouds, sea ice or vehicles. For future applications, acquisition plans of existing and upcoming airborne and spaceborne missions could be modified to target selected sites at specific times (e.g., Kääb et al. 2013). In this context, unmanned airborne vehicles and systems (UAV, UAS) offer cheap and flexible solutions. The method demonstrated here relies on angular time-lag constellations that were for the most part not meant for motion tracking or where angular differences or related time-lags are even considered a drawback.

\section{Acknowledgements}

The providers of the data used in this study are much acknowledged. ASTER data were obtained from NASA through Reverb/ECHO under the GLIMS project (www.glims.org); ALOS PRISM data from ESA under AOALO.3579; WorldView-2 and Ikonos data from DigitalGlobe; USGS airphoto, Landsat and EO-1 ALI data from the USGS (earthexplorer.usgs.gov), RapidEye sample data from Blackbridge (www.blackbridge.com/rapideye), and the airphotos over Yukon River from Matt Nolan (www.drmattnolan.org). A. Kääb was supported by the Research Council of Norway (contracts 185906/V30 and SFF-ICG 146035/420) and the European Research Council under the European Union's Seventh Framework Programme (FP/20072013) / ERC grant agreement no. 320816. S. Leprince was supported by the Gordon and Betty Moore Foundation through Grant GBM 2808 to the Advanced Earth Observation Project at Caltech.

\section{Appendix A. Additional figures.}

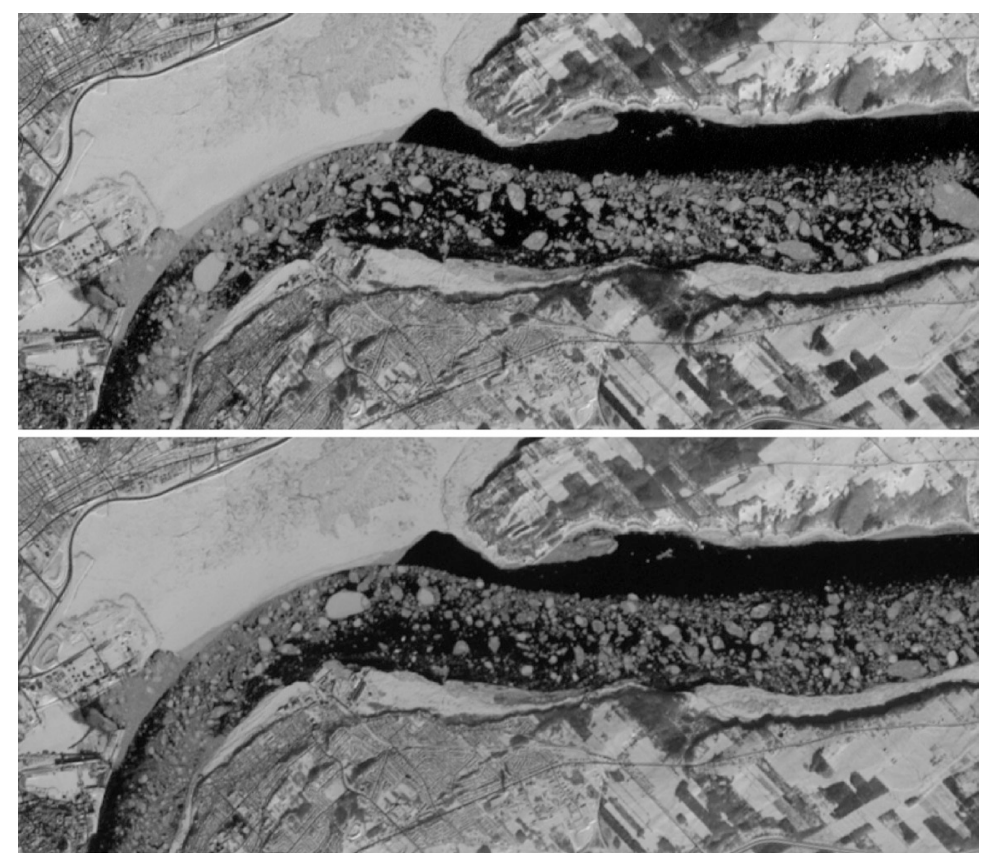

Fig. A1 Landsat (upper) and ASTER (lower) data of the St. Lawrence River at Québec City on 30 January 2003 acquired with a time-lag of about 20 min. (Cf. Fig. 5). 
Kääb A. and Leprince S. (2014): Motion detection using near-simultaneous satellite acquisitions.

Remote Sensing of Environment, 154, 164-179. DOI: 10.1016/j.rse.2014.08.015 (Initial manuscript version).

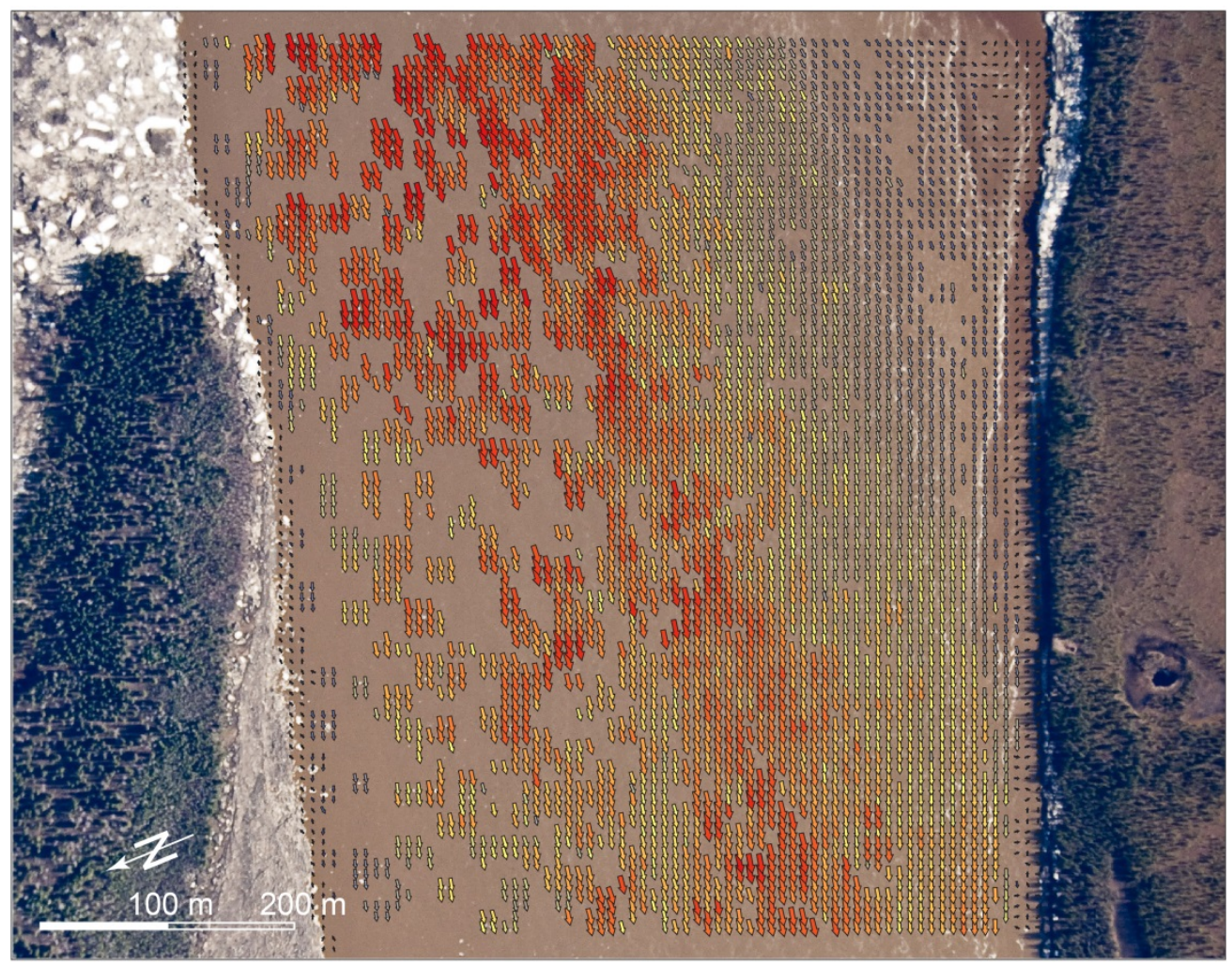

Fig. A2 Colour-coded displacement vectors of fine river-ice debris on the Yukon River near Eagle, Alaska, USA. The two overlapping airborne frame images were taken by Matt Nolan on 13 May 2009 with a time lag of about $6 \mathrm{~s}$

(www.drmattnolan.org). For the test shown here the images were not georeferenced, but rather one image registered on the other using river shore points. The image pixel size on the river level is approximately $0.4 \mathrm{~m}$, though not uniformly due to the perspective distortion of the master image not being removed. The maximum displacement over the $\sim 6 \mathrm{~s}$ time-lag translates to roughly $2.7 \mathrm{~m} \mathrm{~s}^{-1}$ maximum water velocity. Central latitude/longitude $\sim 65.36^{\circ} \%-142.36^{\circ}$.
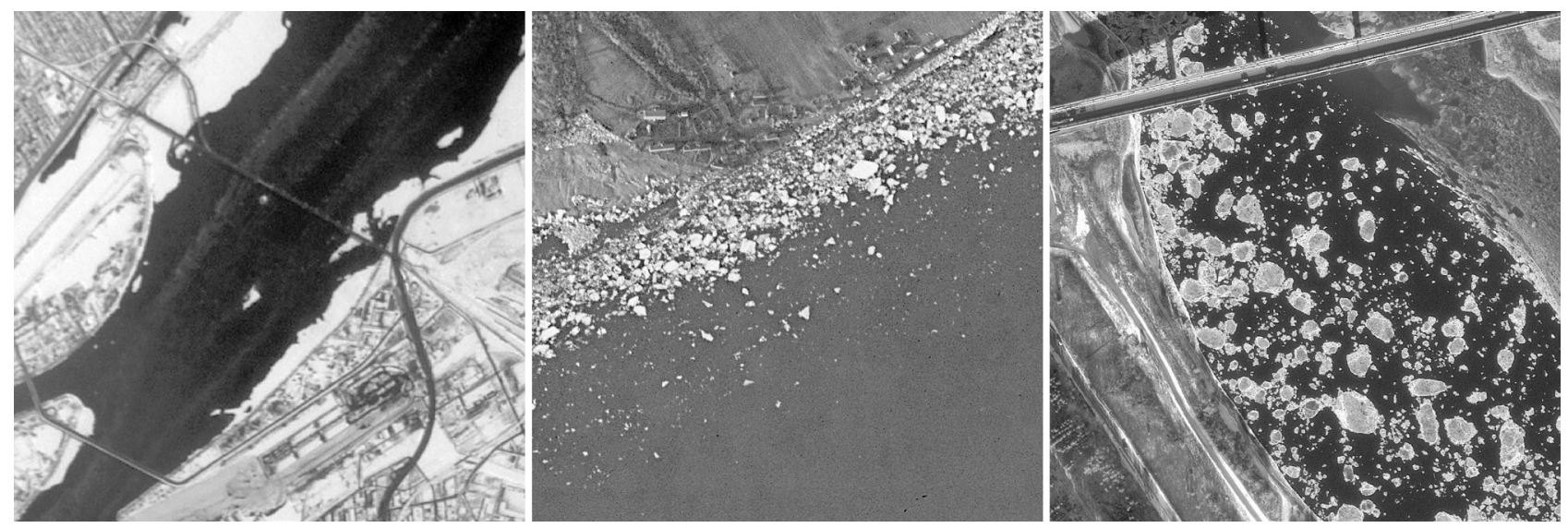

Fig. A3 Details of near-simultaneous space imagery with moving river ice debris. Only one point in time shown. Left: Astronaut photo sequence taken from the International Space Station over the St. Lawrence River, Canada. Middle: Corona declassified stereo photo over Yenisei River, Russia, after ice break-up. Right: GeoEye-1 in-track stereo image over Athabasca River, Canada, during freeze-up. 
Kääb A. and Leprince S. (2014): Motion detection using near-simultaneous satellite acquisitions.

Remote Sensing of Environment, 154, 164-179. DOI: 10.1016/j.rse.2014.08.015 (Initial manuscript version).

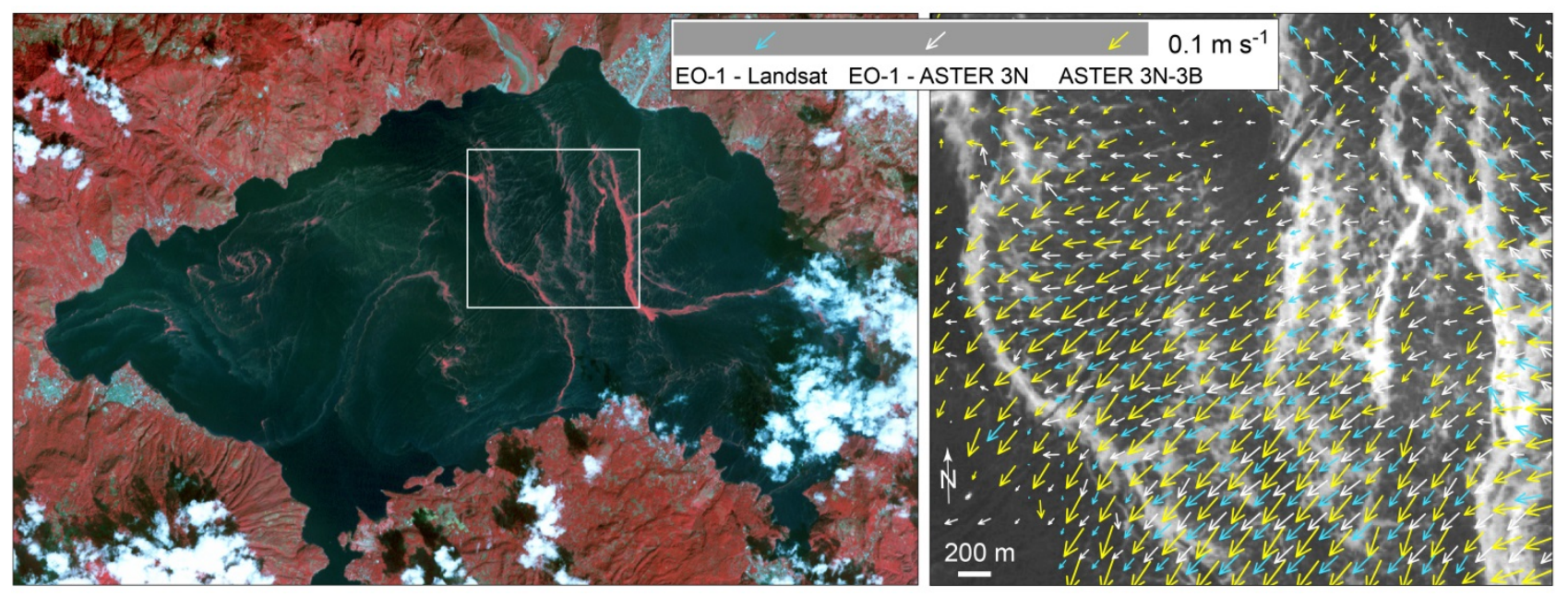

Fig. A4 Surface velocities of a bloom of blue-green algae on Lake Atitlán, Guatemala, on 1 December 2009. The displacements are derived from a sequence of EO-1 ALI data ( $t=0)$, Landsat7 ETM+ data ( $t \approx 14 \mathrm{~min})$, ASTER $3 N$ data $(t \approx 41 \mathrm{~min})$, and $A S T E R 3 B$ data $(t \approx 41 \mathrm{~min}+55 \mathrm{~s})$. Left: Lake Atitlán in the ASTER VNIR false colour composite. Right: Detail of three velocity fields with the ALI pan data in the background. The velocity fields shown differ from each other in parts at a statistically significant level. Central latitude/longitude $\sim 14.7^{\circ} /-91.16^{\circ}$.

\section{References}

Baumgartner, S.V., \& Krieger, G. (2011). Large along-track baseline SAR-GMTI: first results with the Terrasar$\mathrm{X} /$ Tandem-X satellite constellation. IGARSS 2011, IEEE International Geoscience and Remote Sensing Symposium, 1319-1322

Beltaos, S., \& Kääb, A. (2014). Estimating river discharge during ice breakup from near-simultaneous satellite imagery. Cold Regions Science and Technology, 98, 35-46

Bjerklie, D.M., Moller, D., Smith, L.C., \& Dingman, S.L. (2005). Estimating discharge in rivers using remotely sensed hydraulic information. Journal of Hydrology, 309, 191-209

Brown, L.G. (1992). A survey of image registration techniques. Computing Surveys, 24, 325-376

Chickadel, C.C., Talke, S.A., Horner-Devine, A.R., \& Jessup, A.T. (2011). Infrared-based measurements of velocity, turbulent kinetic energy, and dissipation at the water surface in a tidal river. IEEE Geoscience and Remote Sensing Letters, 8, 849-853

Creutin, J.D., Muste, M., Bradley, A.A., Kim, S.C., \& Kruger, A. (2003). River gauging using PIV techniques: a proof of concept experiment on the Iowa River. Journal of Hydrology, 277, 182-194
De Michele, M., Leprince, S., Thiebot, J., Raucoules, D., \& Binet, R. (2012). Direct measurement of ocean waves velocity field from a single SPOT-5 dataset. Remote Sensing of Environment, 119, 266-271

Debella-Gilo, M., \& Kääb, A. (2011). Sub-pixel precision image matching for measuring surface displacements on mass movements using normalized cross-correlation. Remote Sensing of Environment, 115, 130-142

Debella-Gilo, M., \& Kääb, A. (2012). Measurement of surface displacement and deformation of mass movements using least squares matching of repeat high resolution satellite and aerial images. Remote Sensing, 4, 43-67

Diner, D.J., Davies, R., Di Girolamo, L., Horvath, A., Moroney, C., Muller, J.-P., Paradise, S.R., Wenkert, D., \& Zong, J. (1999). Level 2 cloud detection and classification algorithm theoretical basis. In Jet Propulsion Laboratory, California Institute of Technology (Ed.) (p. 110)

Emery, W.J., Fowler, C.W., \& Maslanik, J.A. (1997). Satellite-derived maps of Arctic and Antarctic sea ice motion: 1988 to 1994. Geophysical Research Letters, 24, $897-900$

Ettema, R., Fujita, I., Muste, M., \& Kruger, A. (1997). Particle-image velocimetry for whole-field measurement of ice velocities. Cold Regions Science and Technology, 26, 97-112 
Kääb A. and Leprince S. (2014): Motion detection using near-simultaneous satellite acquisitions.

Remote Sensing of Environment, 154, 164-179. DOI: 10.1016/j.rse.2014.08.015 (Initial manuscript version).

Fitch, A.J., Kadyrov, A., Christmas, W.J., \& Kittler, J. (2002). Orientation correlation. In, British Machine Vision Conference (pp. 133-142)

Garay, M.J., \& Diner, D.J. (2007). Multi-angle Imaging SpectroRadiometer (MISR) time-lapse imagery of tsunami waves from the 26 December 2004 Sumatra-Andaman earthquake. Remote Sensing of Environment, 107, 256-263

Genkova, I., Pachedjieva, B., Ganev, G., \& Tsanev, V. (1999). Cloud motion estimation from METEOSAT images using Time Mutability Method. Tenth International School on Quantum Electronics: Laser Physics and Applications, 3571, 297-301

Goldstein, R.M., \& Zebker, H.A. (1987). Interferometric radar measurement of ocean surface currents. Nature, 328, 707-709

Heid, T., \& Kääb, A. (2012). Evaluation of existing image matching methods for deriving glacier surface displacements globally from optical satellite imagery. Remote Sensing of Environment, 118, 339-355

Himed, B., \& Soumekh, M. (2006). Synthetic aperture radar-moving target indicator processing of multi-channel airborne radar measurement data. IEEE Proceedings-Radar Sonar and Navigation, 153, 532-543

Horvath, A., \& Davies, R. (2001). Feasibility and error analysis of cloud motion wind extraction from nearsimultaneous multiangle MISR measurements. Journal of Atmospheric and Oceanic Technology, 18, 591-608

Jasek, M., Muste, M., \& Ettema, R. (2001). Estimation of Yukon River discharge during an ice jam near Dawson City. Canadian Journal of Civil Engineering, 28, 856-864

Kääb, A. (2002). Monitoring high-mountain terrain deformation from air- and spaceborne optical data: examples using digital aerial imagery and ASTER data. ISPRS Journal of Photogrammetry and Remote Sensing, 57, 39-52

Kääb, A. (2013). Correlation Image Analysis software (CIAS), http://www.mn.uio.no/icemass. Last visted 5 August 2014.

Kääb, A., Girod, L., \& Berthling, I. (2014). Surface kinematics of periglacial sorted circles using structurefrom-motion technology. The Cryosphere, 8, 1041-1056

Kääb, A., Lamare, M., \& Abrams, M. (2013). River ice flux and water velocities along a $600 \mathrm{~km}$-long reach of Lena River, Siberia, from satellite stereo. Hydrology and Earth System Sciences, 17, 4671-4683

Kääb, A., \& Prowse, T. (2011). Cold-regions river flow observed from space. Geophysical Research Letters, 38, L08403
Kääb, A., \& Vollmer, M. (2000). Surface geometry, thickness changes and flow fields on creeping mountain permafrost: automatic extraction by digital image analysis. Permafrost and Periglacial Processes, 11, 315-326

Lavergne, T., Eastwood, S., Teffah, Z., Schyberg, H., \& Breivik, L.A. (2010). Sea ice motion from low-resolution satellite sensors: An alternative method and its validation in the Arctic. Journal of Geophysical Research-Oceans, 115, C10032

Lee, D.S., Storey, J.C., Choate, M.J., \& Hayes, R.W. (2004). Four years of Landsat-7 on-orbit geometric calibration and performance. IEEE Transactions on Geoscience and Remote Sensing, 42, 2786-2795

Leprince, S., Ayoub, F., Klinger, Y., \& Avouac, J.P. (2007a). Co-registration of Optically Sensed Images and Correlation (COSI-Corr): an operational methodology for ground deformation measurements. IGARSS 2007, IEEE International Geoscience and Remote Sensing Symposium, 1-12, 1943-1946

Leprince, S., Barbot, S., Ayoub, F., \& Avouac, J.P. (2007b). Automatic and precise orthorectification, coregistration, and subpixel correlation of satellite images, application to ground deformation measurements. IEEE Transactions on Geoscience and Remote Sensing, 45, 1529-1558

Matthews, J. (2005). Stereo observation of lakes and coastal zones using ASTER imagery. Remote Sensing of Environment, 99, 16-30

Matthews, J.P., \& Awaji, T. (2010). Synoptic mapping of internal-wave motions and surface currents near the Lombok Strait using the Along-Track Stereo Sun Glitter technique. Remote Sensing of Environment, 114, 1765-1776

May, S., \& Latry, C. (2009). Digital elevation model computation with Spot 5 panchromatic and multispectral images using low stereoscopic angle and geometric model refinement. IGARSS 2009, EEE International Geoscience and Remote Sensing Symposium, 1-5, 2822-2825

Meng, L.F., \& Kerekes, J.P. (2012). Object tracking using high resolution satellite imagery. IEEE Journal of Selected Topics in Applied Earth Observations and Remote Sensing, $5,146-152$

Michel, R., Ampuero, J.P., Avouac, J.P., Lapusta, N., Leprince, S., Redding, D.C., \& Somala, S.N. (2013). A geostationary optical seismometer, proof of concept. IEEE Transactions on Geoscience and Remote Sensing, 51, 695703

Munchow, A., \& Melling, H. (2008). Ocean current observations from Nares Strait to the west of Greenland: Interannual to tidal variability and forcing. Journal of Marine Research, 66, 801-833 
Kääb A. and Leprince S. (2014): Motion detection using near-simultaneous satellite acquisitions.

Remote Sensing of Environment, 154, 164-179. DOI: 10.1016/j.rse.2014.08.015 (Initial manuscript version).

Nuth, C., \& Kääb, A. (2011). Co-registration and bias corrections of satellite elevation data sets for quantifying glacier thickness change. The Cryosphere, 5, 271-290

Palubinskas, G., Runge, H., \& Reinartz, P. (2007). Measurement of radar signatures of passenger cars: airborne SAR multi-frequency and polarimetric experiment. IEEE Radar Sonar and Navigation, 1, 164-169

Pesaresi, M., Gutjahr, K.H., \& Pagot, E. (2008). Estimating the velocity and direction of moving targets using a single optical VHR satellite sensor image. International Journal of Remote Sensing, 29, 1221-1228

Puleo, J.A., McKenna, T.E., Holland, K.T., \& Calantoni, J. (2012). Quantifying riverine surface currents from time sequences of thermal infrared imagery. Water Resources Research, 48, W01527

Rabe, B., Munchow, A., Johnson, H.L., \& Melling, H. (2010). Nares Strait hydrography and salinity field from a 3 -year moored array. Journal of Geophysical ResearchOceans, 115, C07010

Reinartz, P., Lachaise, M., Schmeer, E., Krauss, T., \& Runge, H. (2006). Traffic monitoring with serial images from airborne cameras. ISPRS Journal of Photogrammetry and Remote Sensing, 61, 149-158

Romeiser, R., Breit, H., Eineder, M., Runge, H., Flament, P., de Jong, K., \& Vogelzang, J. (2005). Current measurements by SAR along-track interferometry from a space shuttle. IEEE Transactions on Geoscience and Remote Sensing, 43, 2315-2324

Romeiser, R., Runge, H., Suchandt, S., Sprenger, J., Weilbeer, H., Sohrmann, A., \& Stammer, D. (2007). Current measurements in rivers by spaceborne along-track InSAR. IEEE Transactions on Geoscience and Remote Sensing, 45, 4019-4031

Romeiser, R., Suchandt, S., Runge, H., Steinbrecher, U., \& Grunler, S. (2010). First Analysis of TerraSAR-X AlongTrack InSAR-Derived Current Fields. IEEE Transactions on Geoscience and Remote Sensing, 48, 820-829
Rott, H. (2009). Advances in interferometric synthetic aperture radar (InSAR) in earth system science. Progress in Physical Geography, 33, 769-791

Seiz, G., Baltsavias, M., \& Gruen, A. (2003). Highresolution cloud motion analysis with METEOSAT-6 rapid scans, MISR and ASTER. In, EUMETSAT Conference Proceedings (p. 7). Weimar

Siegmund, R., Bao, M.Q., Lehner, S., \& Mayerle, R. (2004). First demonstration of surface currents imaged by hybrid along- and cross-track interferometric SAR. IEEE Transactions on Geoscience and Remote Sensing, 42, 511519

Smith, L.C. (2002). Emerging applications of interferometric synthetic aperture radar (InSAR) in geomorphology and hydrology. Annals of the Association of American Geographers, 92, 385-398

Strozzi, T., Luckman, A., Murray, T., Wegmuller, U., \& Werner, C.L. (2002). Glacier motion estimation using SAR offset-tracking procedures. IEEE Transactions on Geoscience and Remote Sensing, 40, 2384-2391

Takasaki, K., Sugimura, T., \& Tanaka, S. (1993). Speed vector measurement of moving-objects using JERS-1 OPS data. IGARSS 1993, IEEE International Geoscience and Remote Sensing Symposium, 1-4, 476-478

Vincent, F., Raucoules, D., Degroeve, T., Edwards, G., \& Mostafavi, M.A. (2004). Detection of river/sea ice deformation using satellite interferometry: limits and potential. International Journal of Remote Sensing, 25, 3555-3571

Wohlleben, T., Howell, S.E.L., Agnew, T., \& Komarov, A. (2013). Sea-ice motion and flux within the Prince Gustaf Adolf Sea, Queen Elizabeth Islands, Canada during 2010. Atmosphere-Ocean, 51, 1-17

Zitova, B., \& Flusser, J. (2003). Image registration methods: a survey. Image and Vision Computing, 21, 9771000 . 